\title{
Macroscopic and Microscopic Properties of a Cloned Glutamate Transporter/Chloride Channel
}

\author{
Jacques I. Wadiche and Michael P. Kavanaugh \\ Vollum Institute, Oregon Health Sciences University, Portland, Oregon 97201
}

The behavior of $\mathrm{a} \mathrm{Cl}^{-}$channel associated with a glutamate transporter was studied using intracellular and patch recording techniques in Xenopus oocytes injected with human EAAT1 cRNA. Channels could be activated by application of glutamate to either face of excised membrane patches. The channel exhibited strong selectivity for amphipathic anions and had a minimum pore diameter of $\sim 5 \AA$. Glutamate flux exhibited a much greater temperature dependence than $\mathrm{Cl}^{-}$flux. Stationary and nonstationary noise analysis was consistent with a sub-femtosiemen $\mathrm{Cl}^{-}$conductance and a maximum channel
$P_{\mathrm{o}} \ll 1$. The glutamate binding rate was similar to estimates for receptor binding. After glutamate binding, channels activated rapidly followed by a relaxation phase. Differences in the macroscopic kinetics of channels activated by concentration jumps of L-glutamate or D-aspartate were correlated with differences in uptake kinetics, indicating a close correspondence of channel gating to state transitions in the transporter cycle.

Key words: glutamate transporter; uptake; kinetics; astrocyte; postsynaptic; chloride channel
Glutamate is the primary excitatory neurotransmitter at central synapses, and its effects on receptors are terminated by diffusion and by the actions of glutamate transporters. These molecules are members of a large amino acid transporter gene family (Malandro and Kilberg, 1996), and they exhibit discrete anatomical localizations. GLAST (EAAT1) and GLT-1 (EAAT2) are found primarily in glial cells, whereas EAAC1 (EAAT3), EAAT4, and EAAT5 are primarily expressed in neuronal cells (Rothstein et al., 1994; Lehre et al., 1995; Yamada et al., 1996; Eliasof et al., 1998). Glutamate transport is electrogenic and coupled to sodium and proton influx and potassium efflux (Kanner and Sharon, 1978; Stallcup et al., 1979; Nelson et al., 1983; Barbour et al., 1988; Zerangue and Kavanaugh, 1996a). In addition to the coupled transport current, a substrate-activated chloride current has been observed in oocytes expressing cloned glutamate transporters (Fairman et al., 1995; Wadiche et al., 1995b; Arriza et al., 1997; Eliasof et al., 1998). The ratio of the glutamate flux current to anion current varies among known glutamate transporters $($ EAAT2 $>$ EAAT3 $>$ EAAT1 $>$ EAAT4 $\approx$ EAAT5 $)$ A similar glutamate-dependent anion current is also observed in neurons and glia (Sarantis et al., 1988; Grant and Dowling, 1995; Picaud et al., 1995b; Billups et al., 1996; Eliasof and Jahr, 1996; Larsson et al., 1996; Bergles and Jahr, 1997; Bergles et al., 1997; Otis et al., 1997). Although the physiological role of the chloride flux is unclear, in retinal neurons this current may play a role in visual processing (Grant and Dowling, 1995; Picaud et al., 1995a). In brain slice preparations, transporter-associated anion currents have been used to monitor the dynamics of synaptically released glutamate (Bergles and Jahr, 1997; Bergles et al., 1997; Otis et al., 1997).

\footnotetext{
Received May 11, 1998; revised July 6, 1998; accepted July 16, 1998.

This work was supported by National Institutes of Health. We thank D. Bergles, J. Diamond, J. Dzubay, S. Eliasof, and M. Jones for discussions. We thank T. Otis and C. Jahr for discussions and sharing unpublished data, and J. Arriza and S. Amara for the EAAT1 cDNA.

Correspondence should be addressed to Michael Kavanaugh, Vollum Institute, L-474, Oregon Health Sciences University, Portland, OR 97201.

Copyright (C) 1998 Society for Neuroscience $0270-6474 / 98 / 187650-12 \$ 05.00 / 0$
}

The molecular and biophysical basis of the chloride conductance is unclear, but it appears to be associated with all eukaryotic glutamate transporters as well as with a neutral amino acid transporter belonging to the same gene family (Zerangue and Kavanaugh, 1996b). This study was designed to compare and contrast the properties of the channel and transport functions of EAAT1, a human glutamate transporter in which these functions can be readily resolved (Wadiche et al., 1995b). The results suggest that chloride and glutamate $/ \mathrm{Na}^{+} / \mathrm{K}^{+} / \mathrm{H}^{+}$permeate by two distinct mechanisms, although the chloride channel gating is intrinsically linked to state transitions in the transporter cycle.

\section{MATERIALS AND METHODS}

Transporter expression and intracellular recording. Capped mRNA transcribed from the cDNA encoding the human brain glutamate transporter EAAT1 (Arriza et al., 1993) was injected into stage V-VI Xenopus oocytes ( $\sim 50-150 \mathrm{ng} /$ oocyte). Membrane currents were recorded 2-5 d later. Recording solution (frog Ringer's solution) contained $96 \mathrm{mM} \mathrm{NaCl}$, $2 \mathrm{~mm} \mathrm{KCl}, 1 \mathrm{~mm} \mathrm{MgCl}_{2}, 1.8 \mathrm{~mm} \mathrm{CaCl}_{2}$, and $5 \mathrm{~mm} \mathrm{HEPES,} \mathrm{pH} \mathrm{7.4,}$ unless stated otherwise. Two electrode voltage-clamp recordings were performed at $22^{\circ} \mathrm{C}$ (unless stated otherwise) with a Geneclamp 500 interfaced to an IBM-compatible PC using a Digidata 1200 A/D controlled with the pCLAMP 6.0 program suite (Axon Instruments, Foster City, CA). The currents were low-pass-filtered at $1 \mathrm{kHz}$ and digitized at $5 \mathrm{kHz}$. Microelectrodes were filled with $3 \mathrm{M} \mathrm{KCl}$ and had tip resistances of $<1 \mathrm{M} \Omega$. The bath was connected to ground by a $3 \mathrm{M} \mathrm{KCl}$-agar bridge from the recording chamber to a $3 \mathrm{M} \mathrm{KCl}$ reservoir containing a $\mathrm{Ag} / \mathrm{AgCl}$ electrode. The voltage-dependence of currents induced by glutamate was determined by subtraction of control currents from currents recorded in the presence of glutamate during $200 \mathrm{msec}$ pulses to different test potentials. The equilibrium potential for chloride was calculated assuming $\left[\mathrm{Cl}^{-}\right]_{\text {in }}=41 \mathrm{~mm}$ (Wadiche et al., 1995b).

Radiotracer flux measurement. Membrane currents were recorded in voltage-clamped oocytes during bath perfusion of $100 \mu \mathrm{M}\left[{ }^{3} \mathrm{H}\right] \mathrm{D}$ aspartate $(0.42 \mathrm{Ci} / \mathrm{mmol})$ (Amersham, Arlington Heights, IL) at indicated membrane potentials. After washout of the radiotracer $(<20 \mathrm{sec})$, oocytes were rapidly transferred into a scintillation tube and lysed, and radioactivity was measured. Currents were recorded using Chart software (ADInstruments, New Castle, NSW, Australia), and integrated currents were compared with radiolabel flux in the same oocytes. Control measurements of radioactivity incorporated into uninjected oocytes represented $<8 \%$ of uptake into oocytes expressing EAAT1. The nonspe- 
A
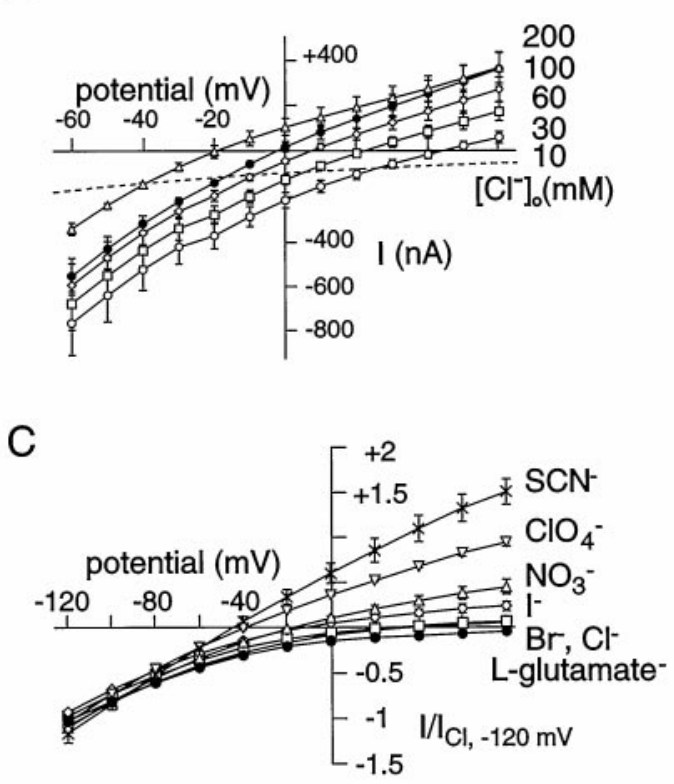

B
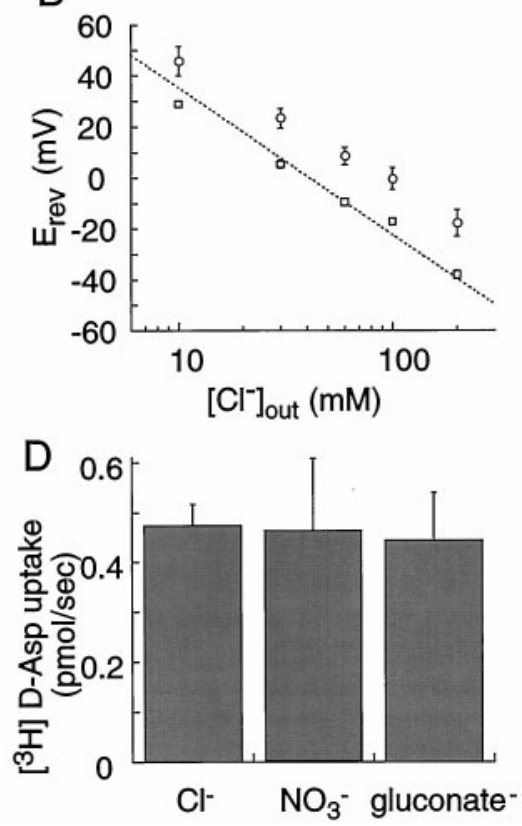

Figure 1. Two currents are mediated by EAAT1. $A$, Average currents induced by 100 $\mu \mathrm{M}$ D-aspartate application on oocytes expressing EAAT1 with recording solutions containing various $\mathrm{Cl}^{-}$concentrations $(\bigcirc, 10 \mathrm{mM}$; $\square, 30 \mathrm{~mm}$; $\diamond, 60 \mathrm{~mm}$ ○, $100 \mathrm{~mm}$; $\triangle, 200 \mathrm{~mm})$. The dashed line corresponds to the predicted coupled uptake current for this group of cells. It represents the mean of exponential fits $(e$ fold, $89.7 \pm 16.4 \mathrm{mV} ; n=5$ ) through current values at the respective chloride equilibrium potentials. Recording solutions were standard Ringer's solutions with gluconate substitution for $\mathrm{Cl}^{-}$to obtain the indicated chloride concentration. Tris-Cl (100 mM) was added to the solutions in experiments with $\mathrm{Cl}^{-}=200 \mathrm{~mm}$. The equilibrium potential for chloride is +35 , $+8,-10,-22$, and $-39 \mathrm{mV}$ in $10,30,60,100$, and $200 \mathrm{~mm}$ external chloride, respectively. $B$, The reversal potential of the net current $(O$, $\left.I_{\text {total }}\right)$ and the chloride-dependent current $(\square$, $\left.I_{\text {chloride }}\right)$ induced by $100 \mu \mathrm{M}$ D-aspartate are dependent on $\left[\mathrm{Cl}^{-}\right]_{\text {out }}$. The reversal potentials of the chloride-dependent current $\left(I_{\text {Chloride }}\right)$ were obtained from current-voltage relationships after the calculated uptake current was subtracted from the total D-aspartate currents $\left(I_{\text {total }}\right)$. The dashed line represents the predicted Nernst equilibrium potential for chlo-

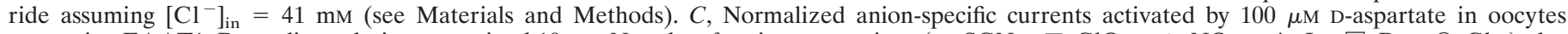

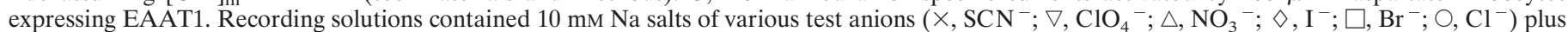

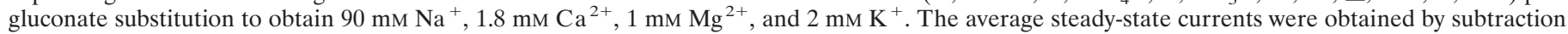

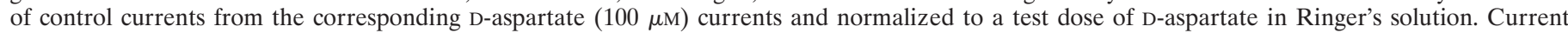

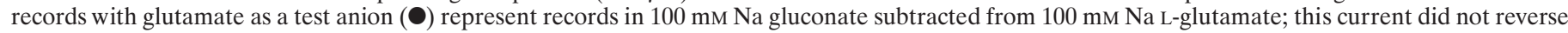

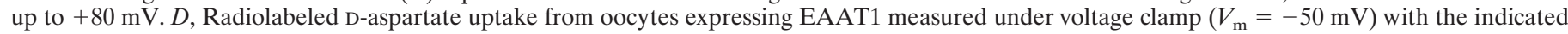
anion substitution $\left(0.47 \pm 0.04,0.46 \pm 0.15\right.$, and $0.44 \pm 0.10 \mathrm{pmol} / \mathrm{sec}$ for $\mathrm{Cl}^{-}, \mathrm{NO}_{3}{ }^{-}$, and gluconate ${ }^{-}$, respectively; $\left.n=4-7\right)$.

cific uptake was subtracted from the total uptake measured in EAAT1expressing oocytes. All data are expressed as mean \pm SE.

Patch recordings. After manual removal of vitelline membrane, insideout or outside-out patch recordings were obtained using pipettes (3-4 $\mathrm{M} \Omega$ ) that were fire-polished and coated with silicone plastic (Sylgard 184, Dow Corning, Midland, MI). Unless stated otherwise, intracellular solution contained $100 \mathrm{mM} \mathrm{KCl}$ or $\mathrm{KSCN}, 10 \mathrm{~mm} \mathrm{KCl}, 3 \mathrm{~mm} \mathrm{MgCl}, 5 \mathrm{~mm}$ Na-HEPES, and $10 \mathrm{~mm}$ EGTA adjusted to $\mathrm{pH} 7.5$ with Tris-base. Extracellular solutions contained $110 \mathrm{~mm} \mathrm{NaCl}$ or $\mathrm{NaSCN}, 3 \mathrm{~mm} \mathrm{MgCl}_{2}$, and $5 \mathrm{~mm} \mathrm{Na-HEPES}$ adjusted to $\mathrm{pH}$ 7.5. Membrane currents were recorded with an Axopatch 200A voltage clamp (Axon Instruments). Solution exchanges were made using a piezoelectric translator (Burleigh Instruments, Fishers, NY) mounted with a drawn glass theta tube (Warner Instruments, Hamden, CT) through which control and experimental solutions flowed continuously. Solution exchange times were measured after each experiment by rupturing the patch and recording junction currents across the open pipette tip. Only patches with membrane seal resistances of $\geq 10 \mathrm{G} \Omega$ were used for noise analysis. The ensemble variance for consecutive sweeps was calculated in bins of three sweeps to minimize any contribution of rundown of the mean current. Steady-state subregions of individual sweeps were also analyzed to verify the magnitude of substrate-dependent changes in variance. The variance induced by injection of a $10 \mathrm{pA}$ current through a $10 \mathrm{G} \Omega$ resistor was $>100$-fold lower than the D-aspartate-induced variance. Records for spectral analysis were low-pass Bessel filtered at $2-5 \mathrm{kHz}$ and digitized at $10 \mathrm{kHz}$. Spectra were calculated on data blocks containing 2048 points. To produce a final spectrum, 50-500 spectra were averaged.

Estimate of unitary conductance-open probability product. The number of transporters per oocyte was estimated from least squares fitting dihydrokainate (DHK)-sensitive charge movement to a Boltzmann function as described in Wadiche et al. (1995a). The glutamate-activated chord anion conductances in the presence of external $\mathrm{Cl}^{-}$or $\mathrm{SCN}^{-}$were measured at various potentials after subtraction of the coupled transport current. At $0 \mathrm{mV}$, the ratio of the chord anion conductance to number of transporters was $1.37 \times 10^{-17} \mathrm{~S} /$ transporter $\left(\mathrm{Cl}^{-}\right)$and $2.65 \times 10^{-16}$ $\mathrm{S} /$ transporter $\left(\mathrm{SCN}^{-}\right)$. At $+80 \mathrm{mV}$, the respective values were $9.08 \times$ $10^{-18} \mathrm{~S} /$ transporter and $2.86 \times 10^{-16} \mathrm{~S} /$ transporter. This value was used to calculate a corrected chord conductance of $6.69 \times 10^{-16} \mathrm{~S} /$ transporter
$(+80 \mathrm{mV})$ for patches in symmetrical $\mathrm{SCN}^{-}$solutions from the Goldman-Hodgkin-Katz (GHK) current equation (Hille, 1992).

Kinetic modeling. A kinetic model was developed using SCoP software (Simulation Resources, Berrien Springs, MI) based on modifications of a cyclical alternating access scheme (Kavanaugh, 1993) with state transition rates fitted or assigned as described in the text.

\section{RESULTS}

\section{Selectivity of the transporter-associated anion conductance}

The EAAT1-dependent current activated by bath application of the transporter substrate D-aspartate has been proposed to be composed of an inward current resulting from movement of thermodynamically coupled ions with glutamate together with an uncoupled chloride conductance that is increased during glutamate transport (Wadiche et al., 1995b). In accord with this, the reversal potential of the net D-aspartate current varied with $\left[\mathrm{Cl}^{-}\right]_{\text {out }}$, but was $15-20 \mathrm{mV}$ more positive than $E_{\mathrm{Cl}}$ (Fig. $1 A, B$ ) [also see Wadiche et al. (1995b); Eliasof and Jahr (1996)]. The chloride current was resolved from the coupled transport current based on the assumption that at $E_{\mathrm{C} 1}$ the transporter-mediated chloride current is zero (Wadiche et al., 1995b). The voltagedependence of the coupled transport current was then determined from measurement of D-aspartate-induced inward currents at different $E_{\mathrm{C} 1}$ values by varying $\left[\mathrm{Cl}^{-}\right]_{\text {out }}$ between 10 and 200 mм (Fig. $1 A$ ). The mean inward currents at five different values of $E_{\mathrm{C} 1}$ were fitted to an exponential function (e-fold $-89.7 \pm 16.4$ $\mathrm{mV} ; n=5$ ) (Fig. $1 A$, dashed line). This function is similar to the voltage dependence of $\left[{ }^{3} \mathrm{H}\right] \mathrm{D}$-aspartate uptake (e-fold $-75 \mathrm{mV}$ ) (Wadiche et al., 1995a), consistent with the current at $E_{\mathrm{Cl}}$ reflecting the $\mathrm{Na}^{+} / \mathrm{H}^{+} / \mathrm{K}^{+}$coupled transport current.

Glutamate transporter currents are increased in the presence 


\begin{tabular}{lcc}
\hline \multicolumn{3}{l}{ Table 1. Selectivity of D-aspartate-induced EAAT1 anion conductance } \\
Ion & $E_{\mathrm{rev}}(\mathrm{mV})^{a}$ & $P_{\mathrm{X}} / P_{\mathrm{Cl}}$ \\
\hline Gluconate $^{-}$ & $>+80(3)$ & $<0.08$ \\
Glutamate $^{-}$ & $>+80(2)$ & $<0.08$ \\
$\mathrm{~F}^{-}$ & $>+80(4)$ & $<0.08$ \\
$\mathrm{Cl}^{-}$ & $+34.5 \pm 2.8(4)$ & 1 \\
$\mathrm{Br}^{-}$ & $+11.7 \pm 4.0(3)$ & 2.6 \\
$\mathrm{I}^{-}$ & $-24.2 \pm 2.5(3)$ & 10.8 \\
$\mathrm{NO}_{3}{ }^{-}$ & $-28.5 \pm 1.1(4)$ & 12.8 \\
$\mathrm{ClO}_{4}^{-}$ & $-38.5 \pm 2.0(3)$ & 19.1 \\
$\mathrm{SCN}^{-}$ & $-69.8 \pm 2.1(4)$ & 66.9 \\
\hline
\end{tabular}

$\overline{{ }^{a} \text { Reversal potentials were determined after subtraction of the predicted coupled }}$ transport current from the total current. Recording conditions included various external anions as $10 \mathrm{~mm}$ sodium salts in the presence of $90 \mathrm{~mm} \mathrm{Na}^{+}, 1.8 \mathrm{~mm} \mathrm{Ca}{ }^{2+}$, $1 \mathrm{~mm} \mathrm{Mg}^{2+}, 2 \mathrm{~mm} \mathrm{~K}^{+}$as gluconate salts and $5 \mathrm{~mm}$ HEPES, $\mathrm{pH}$ 7.4. Gluconate ${ }^{-}$, glutamate ${ }^{-}$, and $\mathrm{F}^{-}$were tested at $100 \mathrm{~mm} \mathrm{Na}^{+-}$salts. $P_{\mathrm{X}} / P_{\mathrm{Cl}}$ was calculated from $E_{\mathrm{rev}}=(R T / z F) \ln \left(P_{\mathrm{X}}\left[\mathrm{X}^{-}\right]_{\text {out }} / P_{\mathrm{Cl}}\left[\mathrm{Cl}^{-}\right]_{\text {in }}\right)$ assuming $\left[\mathrm{Cl}^{-}\right]_{\text {in }}$ of $41 \mathrm{~mm}$.

of certain anions, including $\mathrm{SCN}^{-}, \mathrm{ClO}_{4}{ }^{-}$, and $\mathrm{NO}_{3}{ }^{-}$, and $\mathrm{I}^{-}$ (Wadiche et al., 1995b; Billups et al., 1996; Eliasof and Jahr, 1996; Kavanaugh et al., 1997; Otis et al., 1997). With these more permeant anions in the extracellular solution, larger D-aspartateinduced outward currents are observed (Fig. 1C). In contrast, with gluconate as the sole extracellular anion, outward currents were not observed, consistent with the conclusion that it is impermeant (Wadiche et al., 1995b). The relative permeabilities of a number of anions were quantified using the Goldman-HodgkinKatz voltage equation after isolating the anion current by subtraction of the coupled transport current as described above. This approach relies on the assumption that the coupled transport current is not altered by the permeant anion, which was verified by comparing uptake of $\left[{ }^{3} \mathrm{H}\right] \mathrm{D}$-aspartate in the presence of anions more $\left(\mathrm{NO}_{3}{ }^{-}\right.$) and less (gluconate ${ }^{-}$) permeant than $\mathrm{Cl}^{-}$(Fig. $1 D$ ). The ion permeabilities (relative to $\mathrm{Cl}^{-}$) ranged from $<0.08$ to 67 (Table 1). The data show that the minimum pore diameter of the anion channel is $\sim 5 \AA$, corresponding to the diameter of the largest permeant ion measured, $\mathrm{ClO}_{4}{ }^{-}$(Halm and Frizzell, 1992). Significantly, the uncoupled anion conductance was not measurably permeable to L-glutamate, because no outward current was observed on switching from a $96 \mathrm{~mm}$ gluconate extracellular solution to a $96 \mathrm{~mm}$ glutamate one (Fig. $1 C$ ). This result indicates that glutamate flux occurs solely by a cation-coupled mechanism without "short-circuit" permeation occurring via the anion conductance that would diminish the theoretically achievable glutamate gradient.

\section{The transporter anion conductance displays channel- like permeation properties}

The transporter-mediated glutamate flux and the associated anion currents indicate that different anions can permeate at different rates (and directions) without affecting glutamate flux. The anion permeation was investigated further to determine whether its properties were more consistent with channel-like or carrier-like transport. Changes in temperature are predicted to have less effect on uncoupled ion flux through a channel than on carriermediated transport as a consequence of the difference in thermal dependence of ion diffusion compared with the protein conformational changes predicted to accompany carrier gating. Steadystate currents induced by $100 \mu \mathrm{M}$ D-aspartate were examined at temperatures between 5 and $25^{\circ} \mathrm{C}$. The current magnitude decreased with decreasing temperatures at negative potentials, but was much less affected at positive potentials where anion flux is a greater component of the net current (Fig. 2A). An Arrehnius plot of the normalized currents at two potentials is shown in Figure $2 B$. At $E_{\mathrm{Cl}}$, where all of the charge is carried by the coupled uptake current, the currents exhibited a steep dependence on temperature. In contrast, at $+80 \mathrm{mV}$, where the majority of the current is caused by flux of chloride ions, the current was much less dependent on temperature. Uptake of radiolabeled $\left[{ }^{3} \mathrm{H}\right]$ D-aspartate was also compared at 25 and $15^{\circ} \mathrm{C}$ and found to be reduced to the same extent as the coupled uptake current (Fig. $2 B$, filled circles $)$. The temperature coefficient $\left(Q_{10}\right.$ between 10 and $20^{\circ} \mathrm{C}$ ) for the $\mathrm{D}$-aspartate currents was $3.2 \pm 0.2$ and $1.0 \pm 0.1$ at $-30 \mathrm{mV}$ and $+80 \mathrm{mV}$, respectively. These data suggest that the coupled uptake current reflects kinetic processes that involve large energy barriers, whereas the mechanism of chloride flux is more consistent with ionic diff usion through an aqueous medium.

The conductance of an ion-selective channel will generally exhibit a saturable dependence on the permeant ion concentration as a consequence of the interaction between the channel and the ion (Hille, 1992). The conductance-concentration relationship was compared for $\mathrm{Cl}^{-}$and $\mathrm{NO}_{3}{ }^{-}$, two anions with different permeabilities. After subtraction of the coupled transport current, the chord conductance at $+60 \mathrm{mV}$ activated by application of 1 mM D-aspartate was measured as a function of the extracellular anion concentration (Fig. $2 \mathrm{C}$ ). The conductance for both $\mathrm{Cl}^{-}$and $\mathrm{NO}_{3}{ }^{-}$revealed saturable kinetics with $K_{0.5}$ values of $5.7 \pm 0.9 \mathrm{~mm}$ and $54.4 \pm 15.8 \mathrm{mM}$ for $\mathrm{Cl}^{-}$and $\mathrm{NO}_{3}{ }^{-}$, respectively $(n=4)$. The saturation of the anion conductance is consistent with the permeant anion interacting with a site or sites in the transporter pore in contrast to simple diffusion-mediated flux. Multi-ion occupancy and ion-ion interactions are common in many ion channel pores and may be manifested as conductance minimums as the mole fraction of two distinct permeant ions is varied. When the anion conductance was measured in recording solutions containing varying mole fractions of $\mathrm{Cl}^{-}$and $\mathrm{NO}_{3}{ }^{-}$, it was found to change monotonically, yielding no evidence of multiple anion occupancy of the channel pore (Fig. 2D).

\section{Intracellular glutamate activates anion currents in inside-out patches}

The high permeability of anions like $\mathrm{SCN}^{-}$suggested the possibility of measuring an anion current activated by transport in excised inside-out membrane patches containing glutamate transporters. With a $\mathrm{KCl}$-containing pipette (extracellular) solution, inside-out patches were excised into a NaSCN-containing bath (intracellular) solution. Application of L-glutamate or D-aspartate to the internal membrane face induced a voltage-dependent current (Fig. 3). D-Aspartate did not induce any currents in patches excised from uninjected oocytes $(n=4)$. The current-voltage relationship was strongly rectifying in asymmetric anion solutions, consistent with activation of the same anion conductance by forward or reverse transport (Billups et al., 1996; Kavanaugh et al., 1997). Currents in patches were activated by amino acids (300 $\mu \mathrm{M})$ with the order of efficacy D-asp $>$ L-glu $>$ THA $>$ tPDC $>$ D-glu (Fig. $3 B$ and data not shown). The apparent affinity for D-aspartate at the intracellular face was $203 \pm 85 \mu \mathrm{M}(-80 \mathrm{mV}$; $n=5$ patches), $\sim 10$-fold lower than at the extracellular face determined in intact cells $(20.6 \pm 3.0 \mu \mathrm{M} ;-80 \mathrm{mV} ; n=4)$. Furthermore, consistent with previous work demonstrating a requirement for trans-K ${ }^{+}$for transport (Kanner and Sharon, 1978; Barbour et al., 1988; Szatkowski et al., 1990), the D-aspartate current recorded from inside-out patches was found to be dependent on the extracellular cation (Fig. $3 C$ ). With $\mathrm{K}^{+}$as the trans 
A

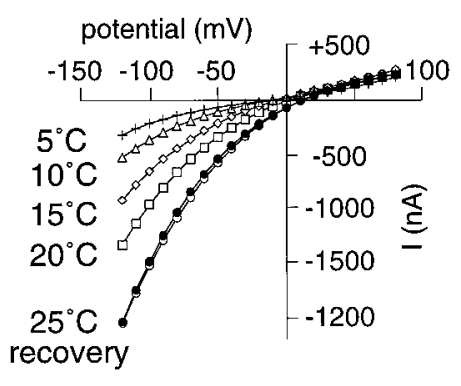

Figure 2. EAAT1 anion conductance properties. $A$, D-Aspartate (1 $\mathrm{mm})$-dependent current-voltage relationship for a representative oocyte expressing EAAT1 at several bath temperatures (recording solution is Ringer's solution). $B$, Arrehnius plot of normalized currents mediated by EAAT1. The temperature coefficients $\left(Q_{10}\right)$ between 10 and $20^{\circ} \mathrm{C}$ are $0.96 \pm 0.1$ and $3.2 \pm 0.2$ at $+80 \mathrm{mV}(\diamond)$ and $-30 \mathrm{mV}\left(\square, E_{\mathrm{Cl}}\right)$, respectively. The $Q_{10}$ for the normalized radiolabeled uptake performed under voltage clamp $(-60 \mathrm{mV})$ was $2.9(\bullet) . C$, Concentration dependence of the anion-specific chord conductance $(+60 \mathrm{mV})$ activated by application of D-aspartate (100 $\mu \mathrm{M})$. Conductances were normalized to the maximum $\mathrm{Cl}^{-}$chord conductance. The apparent $\mathrm{EC}_{50}$ values are $54 \pm 5.4$ and $5.5 \pm 1.6$ mM for $\mathrm{NO}_{3}{ }^{-}$and $\mathrm{Cl}^{-}$, respectively $(n=4)$. $D$, Lack of anomalous mole fraction behavior $\left[\left(\mathrm{NO}_{3}{ }^{-}\right)+\left(\mathrm{Cl}^{-}\right)=3 \mathrm{mM}\right]$ for the anion chord conductance $(+60 \mathrm{mV})$ in cells expressing EAAT1 $(n=3-4)$.
B
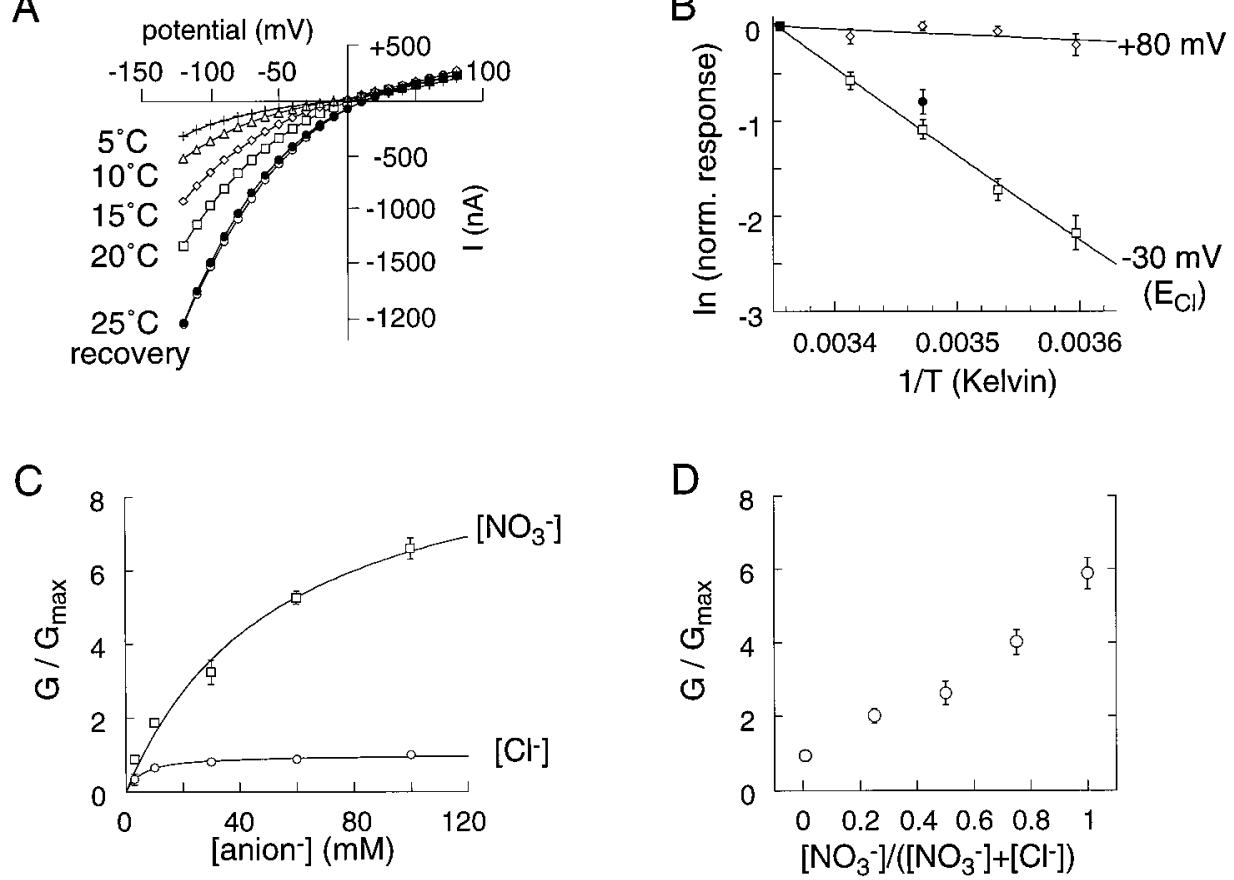

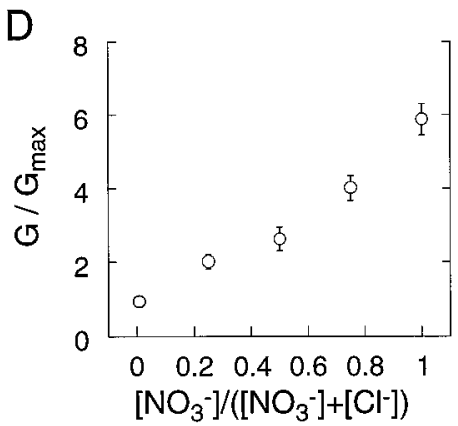

cation, large inward currents were activated by application of 3 $\mathrm{mm}$ D-aspartate. Substitution of $\mathrm{K}^{+}$by choline in the pipette failed to support $\mathrm{D}$-aspartate currents from patches excised from the same oocytes (Fig. $3 C$ ). However, substitution of $\mathrm{K}^{+}$by $\mathrm{Na}^{+}$ supported a D-aspartate-dependent current that was $15-20 \%$ of the magnitude of the trans- $\mathrm{K}^{+}$currents in the same group of oocytes ( $n=4-7$ patches), indicating that $\mathrm{Na}^{+}$is able to partially substitute for $\mathrm{K}^{+}$as a trans cation.

Anion substitution experiments were also performed in insideout patches to compare the permeability of the anion channels activated by internally and externally applied transporter substrates. Steady-state difference currents were measured before and after application of $3 \mathrm{~mm}$ D-aspartate with pipette solutions containing a mixture of $50 \mathrm{~mm} \mathrm{KSCN} / 56 \mathrm{~mm} \mathrm{KCl,} \mathrm{whereas} \mathrm{the}$ bath composition was changed to vary the ratio of $\mathrm{NaCl}$ and $\mathrm{NaSCN}\left(\mathrm{SCN}^{-}+\mathrm{Cl}^{-}=100 \mathrm{~mm}\right)$. A plot of the reversal potentials as a function of the bath (internal) $\mathrm{SCN}^{-}$concentration was fitted by least squares to the GHK voltage equation (Fig. $3 D$ ). Disregarding the coupled transport current, which is not expected to contribute significantly in these conditions, the relative permeability ratio for $\mathrm{SCN}^{-} / \mathrm{Cl}^{-}$was 62.7 , close to the value obtained from whole-cell experiments (66.9) (Fig. 1C, Table 1).

\section{Channel kinetics depend on transported substrates}

To obtain information about the activation and deactivation kinetics of the anion channel, outside-out patches excised from oocytes expressing EAAT1 were held at $-80 \mathrm{mV}$ and exposed to D-aspartate or L-glutamate using a piezo-activated solution exchange system (Maconochie and Knight, 1989). With KSCN in the pipette (intracellular) and $\mathrm{NaCl}$ in the bath (extracellular), inward currents activated by pulses of saturating (10 mM) L-glutamate or D-aspartate exhibited distinct kinetic differences. After the rise to peak, currents evoked by a pulse of L-glutamate decayed significantly more than currents evoked by D-aspartate (Fig. 4A). The decay time constants were $14.1 \pm 2.4 \mathrm{msec}(n=$ $18)$ and $85.4 \pm 15.7 \mathrm{msec}(n=9)$, and the ratios of the peak current to the steady-state current were $1.56 \pm 0.11(n=18)$ and
$1.05 \pm 0.02(n=17)$ for L-glutamate and D-aspartate, respectively. This ratio was voltage-independent for both amino acids (Fig. $4 B, C$ ). At $-80 \mathrm{mV}$, the steady-state response to a saturating pulse of D-aspartate was $1.97 \pm 0.36$ times larger than the L-glutamate response in the same patch $(n=5)$. The activation and deactivation kinetics of the anion current also differed for L-glutamate and D-aspartate, with significantly faster kinetics seen in response to L-glutamate pulses. Rise time constants (determined from exponential fits) (Fig. $5 A)$ were $0.96 \pm 0.07 \mathrm{msec}(n=$ $19)$ and $2.66 \pm 0.22 \mathrm{msec}(n=19)$ for $10 \mathrm{~mm}$ pulses of L-glutamate and D-aspartate, respectively. The deactivation time constant after removal of the amino acid was approximately three times faster for L-glutamate than for D-aspartate $(-80 \mathrm{mV} ; 22.8 \pm 3.9$ msec, $n=9$ vs $75.1 \pm 10.5 \mathrm{msec}, n=9)($ Fig. $4 A, D)$.

The activation rates of the currents were dependent on amino acid concentration. Figure $5 A$ shows representative patch currents induced by application of varying concentrations of L-glutamate between $10 \mu \mathrm{M}$ and $1 \mathrm{~mm}$. An expanded time scale shows the rising phase of the currents (Fig. $5 A$ ). At low concentrations of glutamate, the activation rate was proportional to concentration, whereas at higher concentrations, the rate reached a plateau of $\sim 1000 \mathrm{sec}^{-1}$ (Fig. $5 B$ ). The limiting slope of the activation rate was $6.8 \times 10^{6} \mathrm{M}^{-1} \mathrm{sec}^{-1}$, estimated by linear regression of the activation rates recorded in response to the three lowest concentrations of glutamate (Fig. 5B). This value represents a minimum for the glutamate binding rate constant. After the rise to peak, currents decayed in the continued presence of L-glutamate, with more decay observed at higher concentrations (Fig. 5A). After removal of L-glutamate, the current deactivated in a concentration-independent manner $\left(44 \pm 7 \mathrm{sec}^{-1}\right.$; $n=4$ ) (Fig. 5B).

\section{Predicted unitary properties of EAAT1 currents}

No glutamate-dependent unitary events were seen in patches containing EAAT1 transporters, precluding a direct analysis of the properties of single anion channels. Indirect information about the unitary anion current $(i)$ was therefore obtained from 

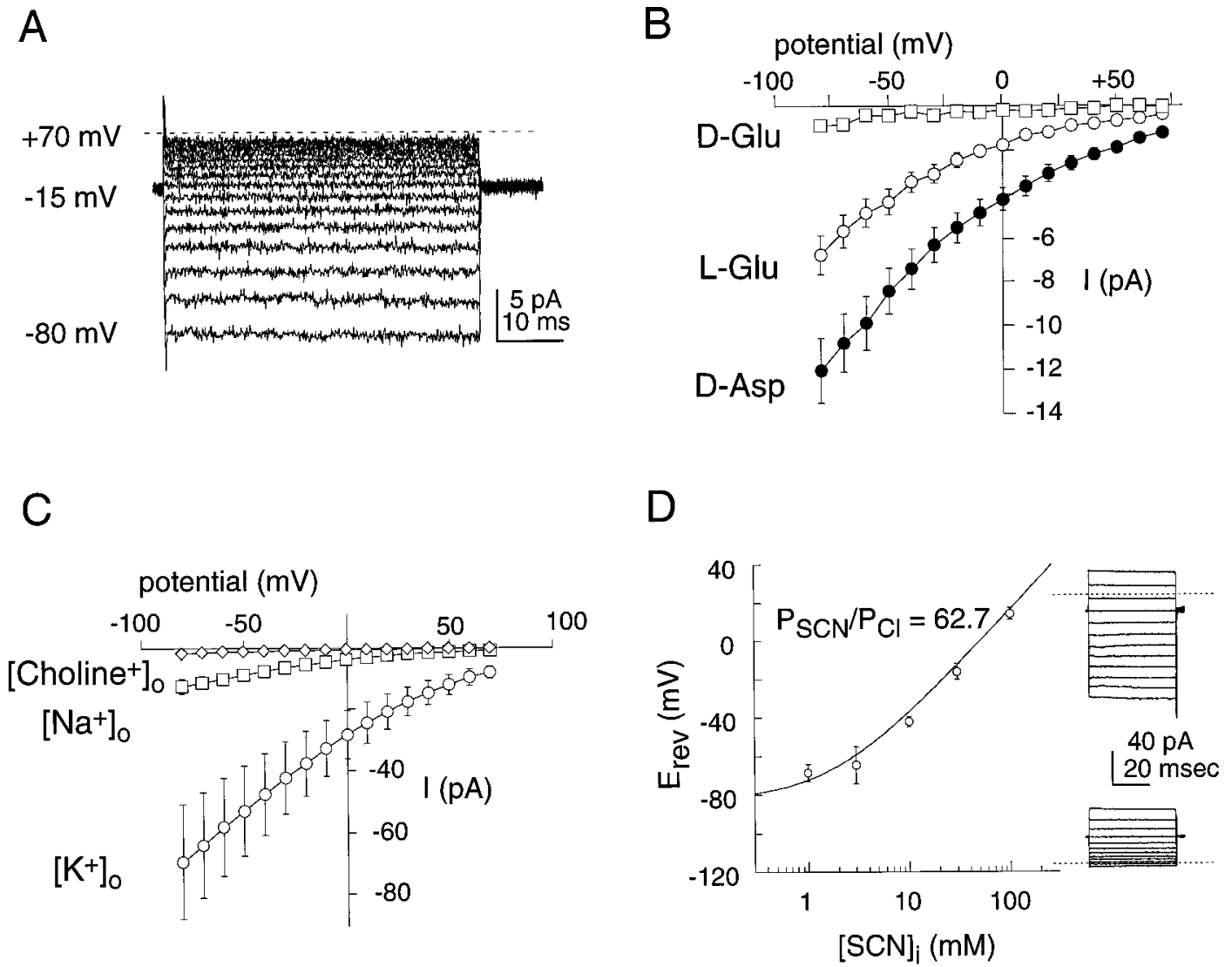

Figure 3. Reverse transport currents in inside-out patches. $A$, Currents in a representative inside-out patch from an EAAT1 oocyte. The currents were obtained by subtraction of control currents from corresponding currents in the presence of $3 \mathrm{~mm} \mathrm{D}$-aspartate $\left(V_{\mathrm{m}}=+70\right.$ and $\left.-80 \mathrm{mV}\right)$. Pipette solution

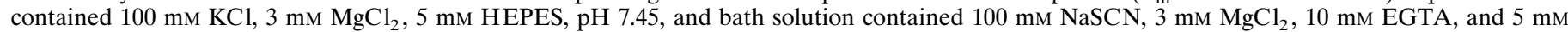
HEPES, pH 7.45. $B$, Voltage dependence of EAAT1-mediated currents ( $n=3$ patches) induced by application of D-glutamate ( $\square$, 3 mM), L-glutamate $(\bigcirc, 3 \mathrm{~mm})$, and D-aspartate $(\bullet, 3 \mathrm{~mm})$. Recording solutions were the same as in $A$. C, Effect of the external (trans) ion on the steady-state D-aspartate (3 mM)-induced currents. Excised inside-out patch currents from EAAT1-expressing oocytes were recorded with pipettes containing 110 mM choline chloride $(\diamond ; n=6), \mathrm{NaCl}(\square ; n=4)$, or $\mathrm{KCl}(n=7)$ plus $3 \mathrm{mM} \mathrm{MgCl}_{2}$ and $5 \mathrm{~mm} \mathrm{HEPES}, \mathrm{pH} 7.4$. Bath solutions contained $100 \mathrm{~mm} \mathrm{NaSCN}, 10 \mathrm{~mm}$ $\mathrm{NaCl}, 3 \mathrm{~mm} \mathrm{MgCl}, 10 \mathrm{~mm}$ EGTA, and $5 \mathrm{~mm}$ HEPES, $\mathrm{pH}$ 7.4. $D$, Relative permeability of SCN/Cl in EAAT1 inside-out patches. Pipettes contained $50 \mathrm{~mm} \mathrm{KSCN} / 56 \mathrm{~mm} \mathrm{KCl}$. The mean reversal potentials for patches $(n=3-9)$ are plotted as a function of the internal SCN ${ }^{-}$concentration. The drawn curve corresponds to nonlinear least squares fit to the function $E_{\mathrm{rev}}=R T / z F \ln \left(\left(P_{\mathrm{SCN}}[\mathrm{SCN}]_{\mathrm{o}}+P_{\mathrm{Cl}}[\mathrm{Cl}]_{\mathrm{o}}\right) /\left(P_{\mathrm{SCN}}[\mathrm{SCN}]_{\mathrm{i}}+P_{\mathrm{Cl}}[\mathrm{Cl}]_{\mathrm{i}}\right)\right)$ and results in a $P_{\mathrm{SCN}} / P_{\mathrm{Cl}}$ of 62.7 . Representative D-aspartate currents in response to voltage jumps in different $[\mathrm{SCN}]_{\text {in }}(30$ and 3 mM) are shown to the right (dotted line represents zero current).

transporter density estimates (Wadiche et al., 1995a) as well as stationary and nonstationary noise analysis (see below) (Anderson and Stevens, 1973; Sigworth, 1980). From measurement of the macroscopic current $(I)$ in a patch or cell containing a number of transporters $(N)$, the product of the open probability and the unitary current amplitude $\left(P_{\mathrm{o}} i\right)$ can be determined because $P_{\mathrm{o}} i=$ $I / N$. The number of transporters was estimated by fitting capacitive charge movements blocked by the nontransported amino acid analog DHK to a Boltzmann function (Wadiche et al., 1995a). In oocytes expressing EAAT1, voltage pulses revealed an analogous transient current blocked by high concentrations of DHK (10 mM) (Fig. 6A, inset). This current was Na-dependent and not seen in uninjected oocytes, and the DHK-sensitive current-time integrals during the voltage pulse were equal to the current-time integral after the return to the holding potential (data not shown) $(r=0.92 \pm 0.2 ; n=7)$. The DHK-sensitive charge movement had an $\mathrm{EC}_{50}$ of $1.43 \pm 0.24 \mathrm{mM}$, close to the affinity estimated from Schild analysis of steady-state L-glutamate currents (data not shown). Finally, the DHK-sensitive transient current-time integrals were saturable and obeyed a Boltzmann function with a
$V_{0.5}=-12.1 \pm 3 \mathrm{mV}$ and slope factor $74.3 \pm 2 \mathrm{mV}$ (Fig. $6 A$ ). The number of transporters was calculated from the charge movement measurement using the equation $N=Q_{\text {total }} / e_{\mathrm{o}} z \delta$, where $Q_{\text {total }}$ represents the total charge movement blocked by a saturating DHK concentration, $e_{\mathrm{o}}$ is the elementary charge $\left(1.6 \times 10^{-19} \mathrm{C}\right)$, and $z \delta$ is the effective valence of the DHK-sensitive charge movement $[R T /(F * 74.3 \mathrm{mV})]$. The average number of transporters in seven oocytes was $4.9 \pm 0.2 \times 10^{11}$. Based on an oocyte surface area of $2.85 \times 10^{7} \mu \mathrm{m}^{2}$ (Wadiche et al., 1995a; Zampighi et al., 1995), this corresponds to an average transporter density of $\sim 17,000 \mu \mathrm{m}^{-2}$. This density is similar to levels of other transport proteins expressed in Xenopus oocytes (Mager et al., 1993; Wadiche et al., 1995a; Zampighi et al., 1995; Klamo et al., 1996). Turnover rates for saturating concentrations (1 $\mathrm{mm})$ of both D-aspartate and L-glutamate were calculated using current measurements and transporter density estimates in individual oocytes assuming the movement of two charges per transport cycle at $E_{\mathrm{Cl}}$, which has been determined for the EAAT3 (Zerangue and Kavanaugh, 1996a,b) and EAAT1 transporters (A. Zable and M. Kavanaugh, unpublished observations). The EAAT1 turnover 
Figure 4. Macroscopic outside-out patch kinetics. $A$, Rapid application of $10 \mathrm{~mm}$ D-aspartate and L-glutamate to a representative outside-out patch from an oocyte expressing EAAT1 $\left(V_{\mathrm{m}}=-80 \mathrm{mV}\right)$. The pipette solution contained $100 \mathrm{~mm} \mathrm{KSCN}, 10$ mM KCl, 3 mM $\mathrm{MgCl}_{2}, 5 \mathrm{~mm}$ HEPES, and $10 \mathrm{~mm}$ EGTA, pH 7.5, whereas the external recording solutions contained $110 \mathrm{~mm}$ $\mathrm{NaCl}, 3 \mathrm{~mm} \mathrm{MgCl}_{2}, 5 \mathrm{~mm}$ HEPES, and 100 $\mu \mathrm{M} \mathrm{LaCl}{ }_{3}$. The application of excitatory amino acids was delivered via flow pipes attached to a piezo-electric device. After the patch was ruptured, the solution exchange time was tested by switching between solutions of different osmolarities. The open tip controls ordinarily had 10 $90 \%$ rise and decay times of $350 \mu \mathrm{sec}$ (shown above current traces). B, Rapid application of L-glutamate $(10 \mathrm{~mm})$ to a representative outside-out patch expressing EAAT1 at the indicated holding potentials. Open tip control is shown above current traces. $C$, Voltage dependence of the peak to steady-state current for L-glutamate (, $10 \mathrm{~mm})$ or D-aspartate $(\bigcirc, 10 \mathrm{~mm}) . D$, Voltage dependence of current deactivation time constant (single exponential) for L-glutamate $(\bullet, 10 \mathrm{~mm})$ or D-aspartate $(\bigcirc$, $10 \mathrm{~mm})$. Only patches with open tip controls of $<500 \mu \mathrm{sec}$ were used for analysis $(10-$ $90 \%$ rise and decay times).
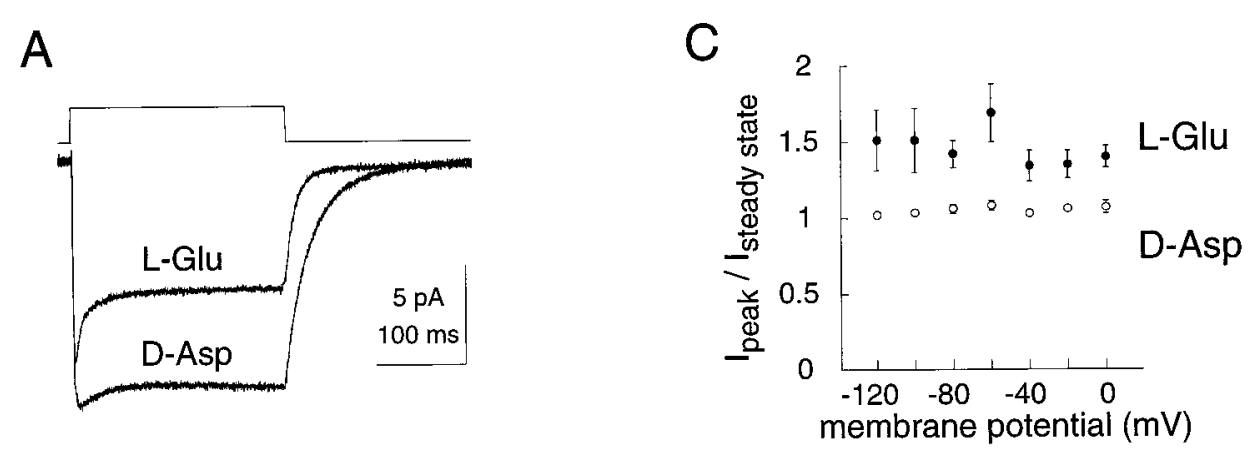

B

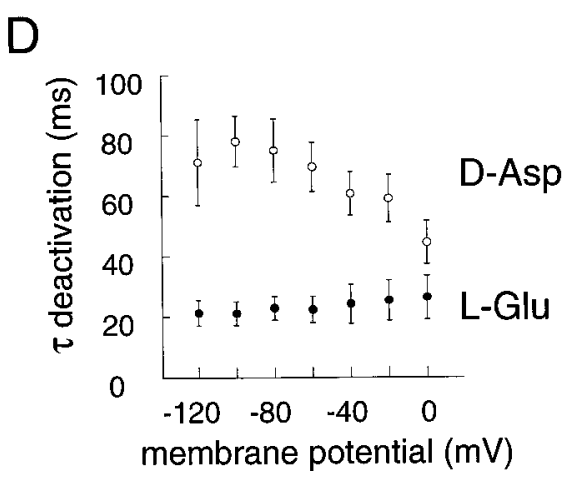

rates were determined to be $4.8 \pm 0.4 \mathrm{sec}^{-1}$ and $10.5 \pm 1.3 \mathrm{sec}^{-1}$ at $-30 \mathrm{mV}$ for D-aspartate and L-glutamate, respectively $(n=7)$. From the voltage dependence of flux (e-fold $89.7 \mathrm{mV}$ ), the extrapolated turnover rates at $-80 \mathrm{mV}$ were 7.3 and $16.0 \mathrm{sec}^{-1}$ for D-aspartate and L-glutamate, respectively.

The transporter density values were used to estimate the anion conductance of single channels, assuming a one-to-one correspondence of transporters and channels. In seven oocytes expressing varying amounts of EAAT1, the D-aspartate-induced chord conductance at $0 \mathrm{mV}$ was calculated after subtracting the coupled transport current from the total current as described above. For each cell, the chord conductance with external solutions containing either $\mathrm{Cl}^{-}$or $\mathrm{SCN}^{-}$was plotted as a function of the number of transporters. Least squares linear fits yielded slopes of 0.014 and $0.265 \mathrm{fS}$ with $\mathrm{Cl}^{-}$and $\mathrm{SCN}^{-}$, respectively (Fig. 6B). These values represent the product of the unitary conductance and open probability for a single transporter $\left(P_{\mathrm{o}} \gamma\right)$. The intrinsic voltage dependence of the transporter anion conductance was also determined by recording D-aspartate currents in symmetrical $\mathrm{SCN}^{-}$recording conditions. The $P_{\mathrm{o}} \gamma$ product at $+80 \mathrm{mV}$ in these conditions was $0.17 \mathrm{fS} /$ transporter. The conductance exhibited a significant inward rectification, with $P_{\mathrm{o}} \gamma_{-100} /$ $P_{\mathrm{o}} \gamma_{+100}=2.14 \pm 0.2(n=7)$ (Fig. $\left.6 C\right)$.

To estimate the independent quantities $P_{\mathrm{o}}$ and $\gamma$, stationary and nonstationary noise analysis of currents induced by D-aspartate in outside-out patches was performed. For these analyses, we used data from patches with high seal resistances $(>10 \mathrm{G} \Omega)$ that exhibited no endogenous channel activity. Patches were held at $0 \mathrm{mV}$ and the pipette solutions contained $\mathrm{SCN}^{-}$, whereas the bath solution contained $\mathrm{Cl}^{-}$. A representative response to a $600 \mathrm{msec}$ application of $10 \mathrm{~mm}$ D-aspartate to an outside-out patch is shown in Figure $6 D$. In this patch, the D-aspartate-induced steady-state current was $12.7 \mathrm{pA}$ at $0 \mathrm{mV}$, corresponding to a $125.6 \mathrm{pS}$ macroscopic chord conductance
$\left(E_{\mathrm{rev}}=+101.1 \mathrm{mV}\right)$. This macroscopic conductance represents $\sim 474,000$ transporters $\left(N=G / P_{\mathrm{o}} \gamma=125.6 \mathrm{pS} / 0.265 \mathrm{fS}\right)$. With $\mathrm{SCN}^{-}$in the recording pipette solution and $\mathrm{Cl}^{-}$in the bath solution, the current induced by $\mathrm{D}$-aspartate was consistently accompanied by a small $\left(\sim 0.02 \mathrm{pA}^{2}\right)$ but significant increase in current noise. This noise was not seen with injection of a similar current into a test resistor (see Materials and Methods). The current induced by pulses of D-aspartate to a patch held at $0 \mathrm{mV}$ and the ensemble variance are shown at the bottom of Figure $6 D$. Assuming that all the channels have a single open state through which current $i$ passes, and that the channels open and close independently of each other, the binomial theorem predicts that the current variance will change according to $\sigma_{\mathrm{I}}^{2}=I i-I^{2} / N$, where $\sigma_{\mathrm{I}}^{2}$ is the increase in variance induced by D-aspartate. In seven patches, the transporter number $N$ was estimated from $I$, and the unitary current $i$ was then determined by measurement of the variance increases caused by D-aspartate application. This method yielded a unitary current estimate of $1.9 \pm 0.4 \mathrm{fA}(n=7)$. Substituting this value of $i$ into the equation $N P_{\mathrm{o}} i=I$ results in a probability of channel opening $\left(P_{\mathrm{o}}\right)$ of $0.016 \pm 0.002$. As an alternative method to investigate the unitary current properties, nonstationary analysis was used. A plot of the macroscopic current versus variance during the D-aspartate washout is shown in Figure $6 E$. The relationship is approximately linear, consistent with the probability of channel opening being very low even at saturating $(10 \mathrm{~mm})$ concentrations of D-aspartate. Fitting the nonstationary variance in patches containing a known number of transporters to $\sigma_{\mathrm{I}}^{2}=I i-I^{2} / N+C$ resulted in $i=1.2 \pm 0.1 \mathrm{fA}$ (Fig. $6 E)(n=3)$. This corresponds to an open probability $\left(P_{\mathrm{o}}\right)$ of $0.022 \pm 0.002(n=3)$. These results are thus consistent with a unitary $\mathrm{SCN}^{-}$conductance between 12 and $19 \mathrm{fS}$, corresponding to a unitary $\mathrm{Cl}^{-}$conductance between 0.63 and $1.0 \mathrm{fS}$.

Spectral analysis of the D-aspartate-induced fluctuations was performed by subtracting the average power spectra of $600 \mathrm{msec}$ 

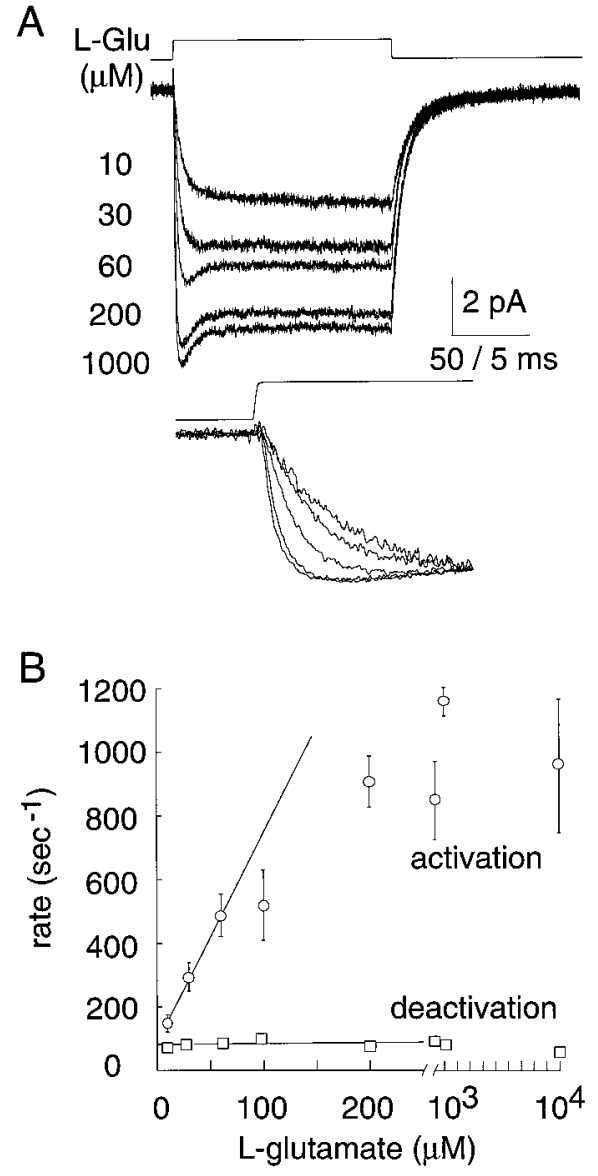

Figure 5. [L-Glutamate] dependence of currents. A, Rapid exchange of various L-glutamate concentrations to a representative EAAT1 expressing outside-out patch. Inset, Normalized currents emphasize the concentration dependence of the current activation rate. $V_{\mathrm{m}}=-80 \mathrm{mV}$. Open tip solution exchange control is shown above current traces $(10-90 \%$ rise $=$ $250 \mu \mathrm{sec}$ ). B, Concentration dependence of the time constant (single exponential) for activation and deactivation of L-glutamate currents $(-80$ $\mathrm{mV} ; n=8$ ). The limiting slope for the activation time constants equals $6.8 \times 10^{6} \mathrm{M}^{-1} \mathrm{sec}^{-1}$.

control records from records during application of $10 \mathrm{~mm}$ D-aspartate (filtered at $2 \mathrm{KHz}$ and acquired at $5 \mathrm{kHz}$ ) (Fig. $6 F$ ). The power spectrum of the induced current did not conform to a single Lorenztian function, unlike that of the transporter current in salamander photoreceptors (Larsson et al., 1996), suggesting that the kinetics of the unitary EAAT1 currents are more complex.

\section{Glutamate-independent conductance}

To determine whether the EAAT1 transporter channel could open in the absence of L-glutamate or D-aspartate, we examined the action of the nontransported glutamate analog DHK on background currents in outside-out patches. With $\mathrm{SCN}^{-}$in the recording pipette, $\mathrm{D}$-aspartate currents were measured with either $\mathrm{Cl}^{-}$or $\mathrm{SCN}^{-}$present extracellularly. As expected for these ionic conditions, the currents induced by amino acid were inward at potentials up to $+60 \mathrm{mV}$ with extracellular $\mathrm{Cl}^{-}$and reversed at $0 \mathrm{mV}$ in symmetrical $\mathrm{SCN}^{-}$solutions (Fig. $7 A_{1}, B$ ). In contrast, application of $10 \mathrm{~mm}$ dihydrokainate resulted in a decrease of a conductance with the same properties as that activated by D-aspartate (Fig. $7 A_{2}, B$ ). Furthermore, the magnitude of the current blocked by dihydrokainate was directly proportional to the magnitude of the current induced by D-aspartate. The conductance decrease at $-80 \mathrm{mV}$ represented $17 \%$ of the conductance activated by D-aspartate (Fig. $7 C$ ). These results indicate that the anion conductance is partially active in the absence of amino acid, similar to conclusions reached by Bergles and Jahr (1997) .

\section{Channel gating and the transport cycle}

A four-state alternating access model with two states corresponding to open channel states (Larsson et al., 1996) was initially used to simulate currents observed during applications of L-glutamate or D-aspartate to outside-out EAAT1 patches. For simplicity, the $\mathrm{Na}^{+} / \mathrm{H}^{+} / \mathrm{Glu}^{-}$bound states were collapsed in the model (represented as TGlu), and the $\mathrm{K}^{+}$binding and countertransport steps were omitted. It was necessary to add two branching anion conducting states to the cyclical four-state model to adequately fit the data (Fig. $8 A$ ). The two extra states correspond to open channel states for the liganded and unliganded transporter. The output of the model is the probability of channel opening, which is equal to the sum of the probabilities that the transporter is in one of these two open states. Several parameters were constrained in the model. (1) The ratio of states $T_{\text {out }}$ and $T_{\text {in }}$ in the absence of glutamate was fixed to $0.8: 0.2$ based on the Boltzmann equilibrium $(-80 \mathrm{mV})$, which suggests that $80 \%$ of the transporters are bound with sodium and ready to bind glutamate (Fig. 6A). (2) The turnover rate $(\tau)$ was assigned to the rate constant $\mathrm{k} 1$. (3) The glutamate-independent probability of channel opening was constrained to be 0.17 of the probability of channel opening in saturating glutamate (Fig. $7 C$ ). (4) The binding rate constant of amino acid was fixed to $6.8 \times 10^{6} \mathrm{M}^{-1} \mathrm{sec}^{-1}$. The remaining free parameters in the kinetic model were allowed to vary, and the output of the model was fitted by least squares to patch data representing normalized average responses to D-aspartate or L-glutamate.

A summary of the kinetic parameters of the simulated and experimental data is given in Table 2, and the output of the simulation for a pulse of L-glutamate or D-aspartate is shown in Figure $8 B$. The principal macroscopic kinetic features of the simulated currents and their amino acid dependence were similar to the experimental data. The open channel probability increases rapidly $\left(\tau_{\text {activation }}=0.9 \mathrm{msec}\right)$ in response to a high concentration of L-glutamate (10 mM). Lower L-glutamate concentrations (1-30 $\mu \mathrm{M})$ elicit currents that rise more slowly, with less inactivation during the agonist pulse (Fig. $8 C$ ). A plot of the time constant of activation as a function of the concentration of L-glutamate results in a relationship similar to experimental results presented in Figure $7 B$. Linear regression yielded a limiting slope at low L-glutamate concentrations of $6.8 \times 10^{6} \mathrm{M}^{-1} \mathrm{sec}^{-1}$, the same value as the model's association rate constant for L-glutamate. This suggests that for this kinetic scheme the rising rate of the current at low agonist concentrations is a good approximation of the binding rate of L-glutamate.

\section{DISCUSSION}

\section{The glutamate transporter anion channel}

Data have accumulated showing that glutamate transport activates an anion conductance both in situ (Grant and Dowling, 1995; Picaud et al., 1995b; Billups et al., 1996; Eliasof and Jahr, 1996; Bergles and Jahr, 1997; Bergles et al., 1997; Otis et al., 1997) and in exogenous expression systems (Fairman et al., 1995; Wadiche et al., 1995a,b). There is an important distinction between the 


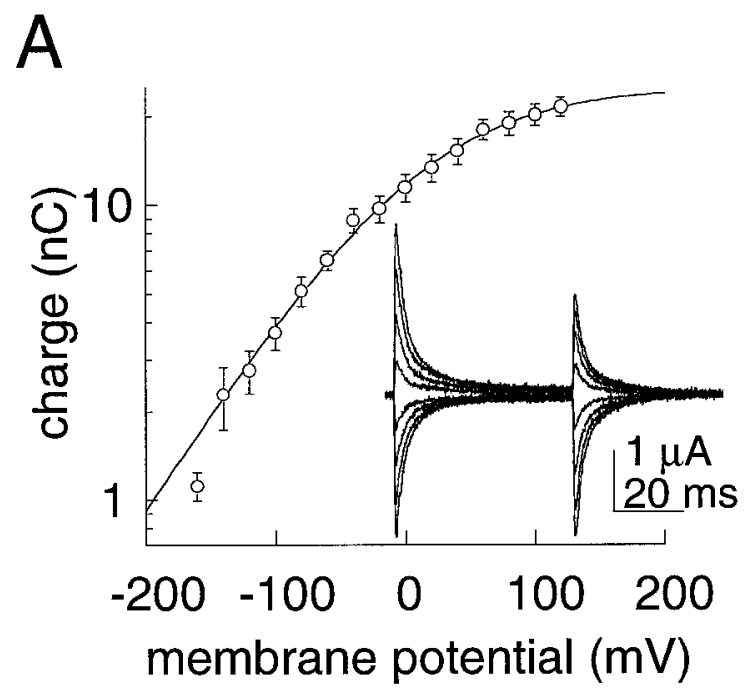

C
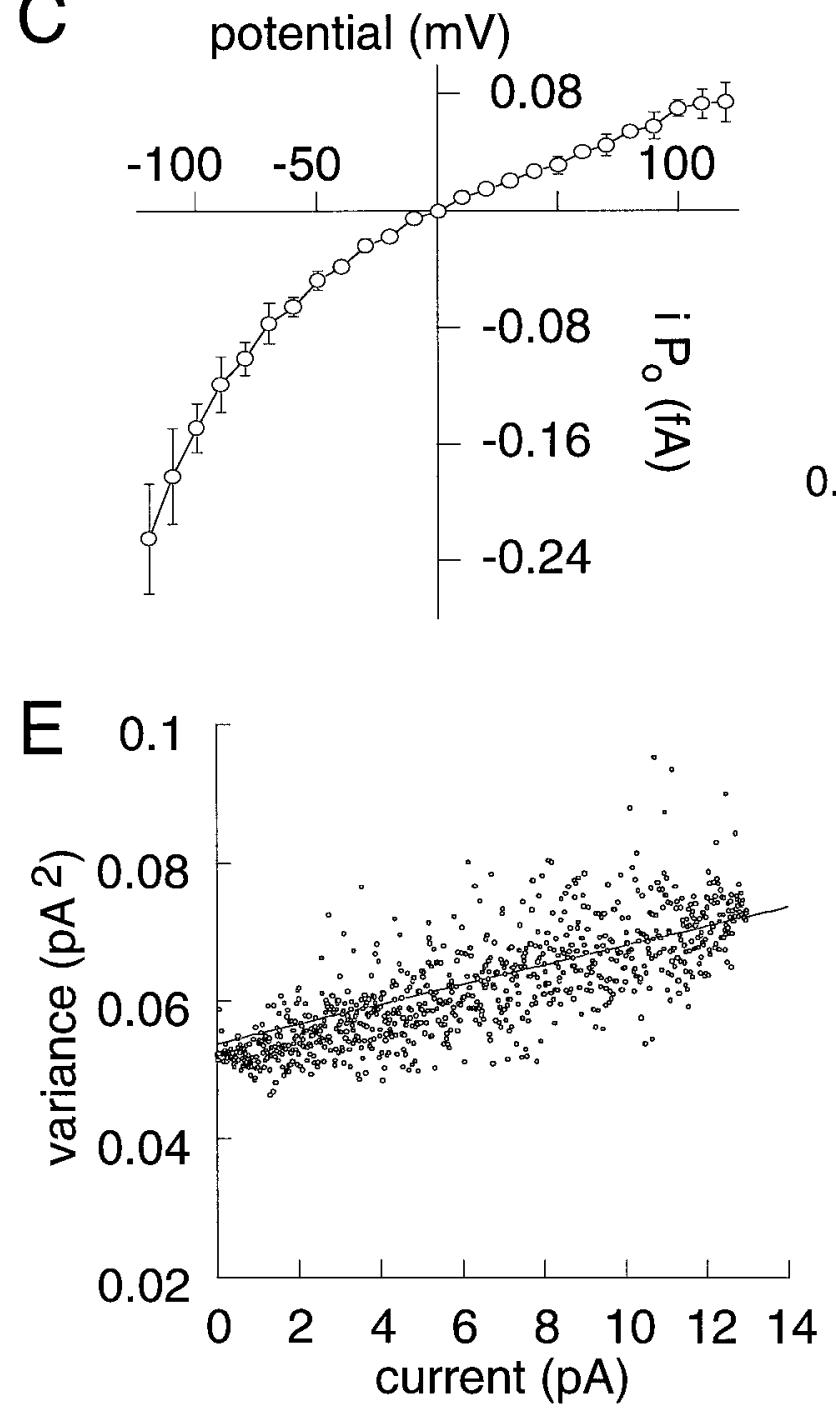

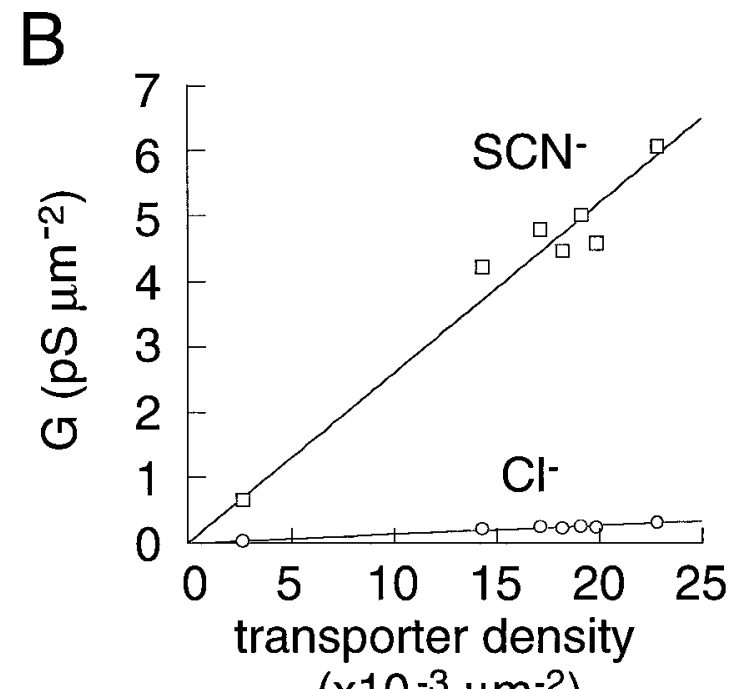

D
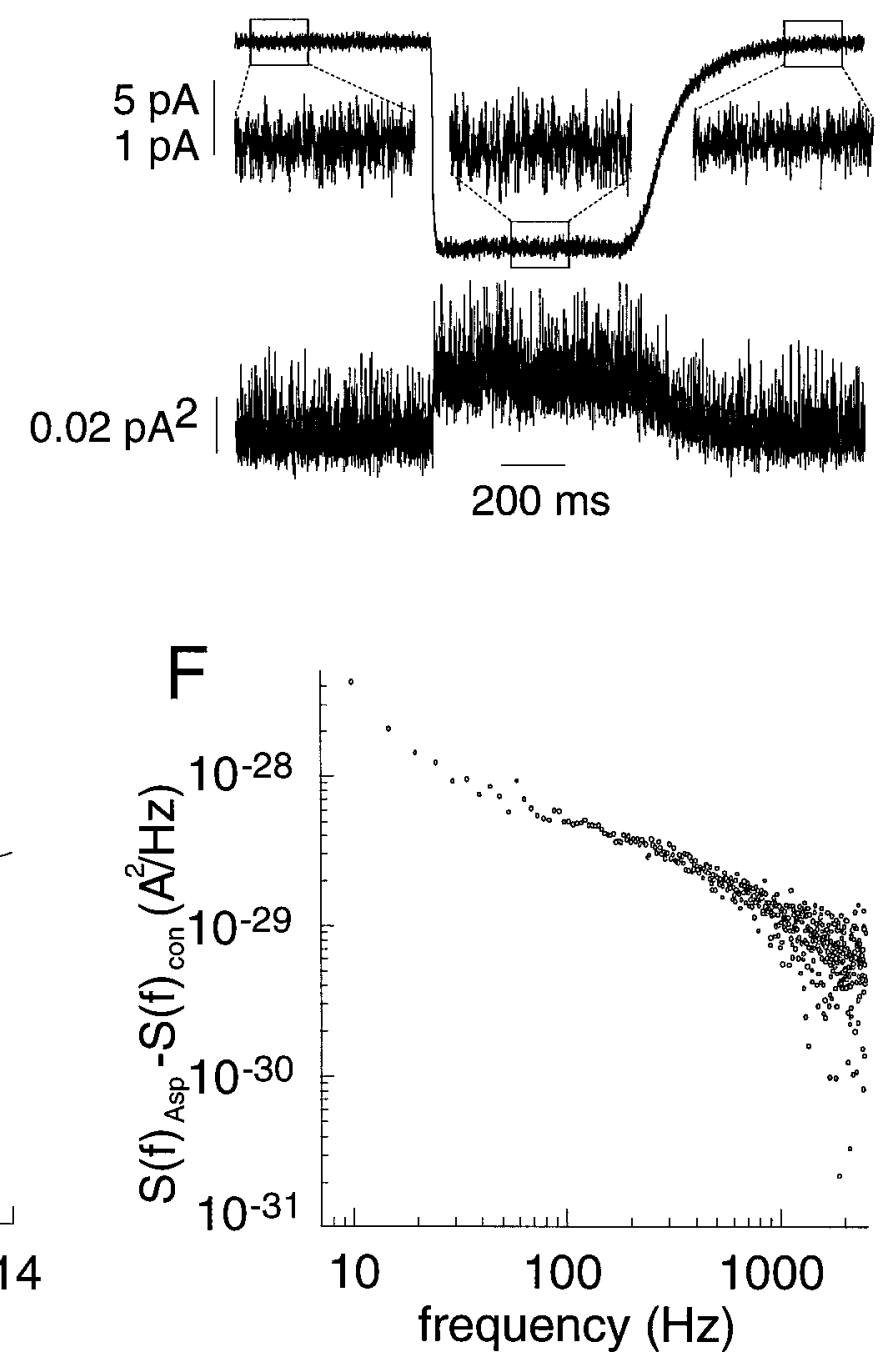

Figure 6. EAAT1 unitary current properties. $A$, Semi-log plot of the charge movements for a group of cells expressing EAAT1 $\left(Q_{\max }=26.3 \pm 1.2 \mathrm{nC}\right)$. The data were fit to a Boltzmann function with a $V_{0.5}=-12.1 \pm 3 \mathrm{mV}$ and slope factor $74.3 \pm 2 \mathrm{mV}(z \delta=R T / F * 74.3=0.34)$. The DHK concentration dependence of the normalized charge movements $\left(\mathrm{EC}_{50}\right.$ for DHK block) is $1.43 \pm 0.24 \mathrm{~mm}$ (data not shown, $\left.n=4\right)$. Inset, Subtracted current record showing the voltage dependence of transient currents blocked by $10 \mathrm{~mm}$ DHK. Voltage command pulses in $40 \mathrm{mV}$ increments (Figure legend continues) 
$A_{1}$

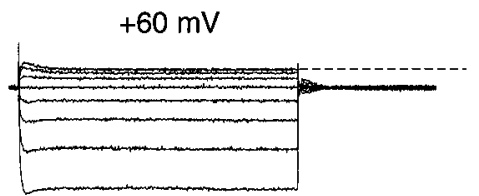

$-80 \mathrm{mV}$
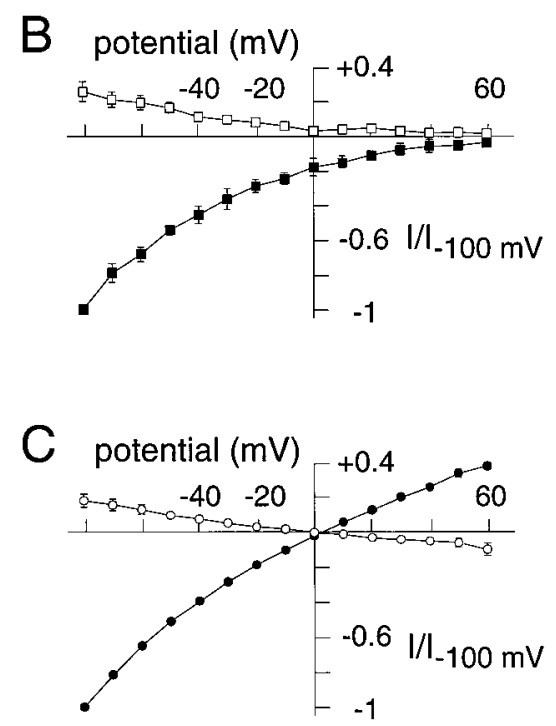
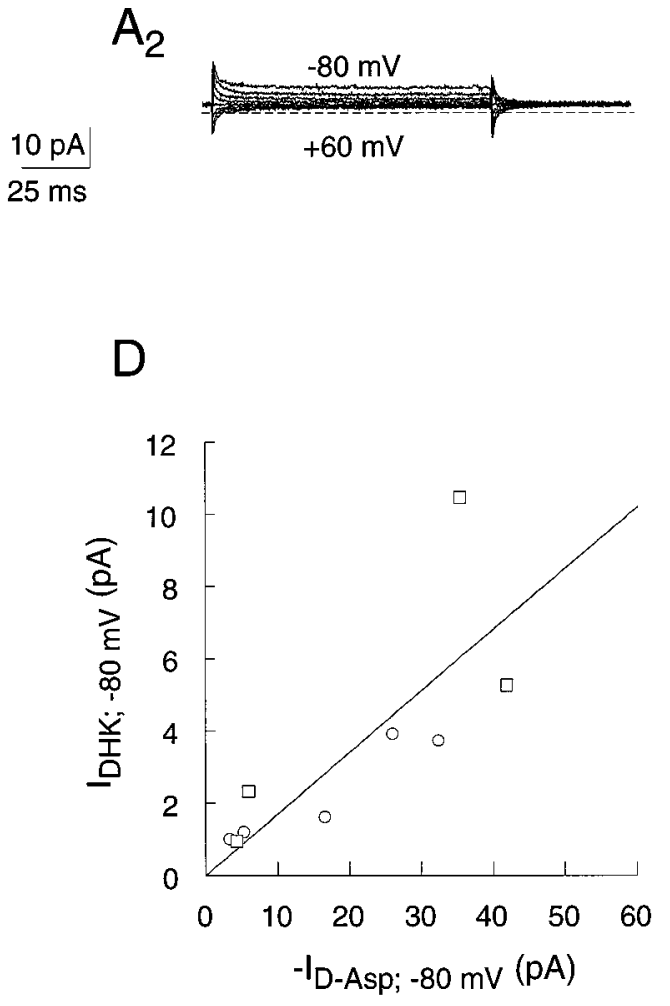

Figure 7. Agonist-independent EAAT1 anion currents. $A_{1}$, Representative outside-out patch recording of steadystate D-aspartate $(10 \mathrm{mM})$-induced currents from an EAAT1-expressing oocyte. $A_{2}$, Record of the DHK blocked current $(10 \mathrm{mM})$ from the same patch as in $A_{1}$. Records of both currents were measured in asymmetrical anion solutions (see below). B, Current-voltage plots of steady-state difference currents induced or blocked by application of $\mathrm{D}$-aspartate $(10 \mathrm{mM}$; filled symbols $; n=4)$ or DHK (10 mM; open symbols; $n=4)$. Outside-out patches expressing EAAT1 were recorded in asymmetrical anionic solutions $\left[(110 \mathrm{~mm} \mathrm{Cl})_{\text {out }}\right.$ and $(100 \mathrm{~mm}$ $\left.\mathrm{SCN}+10 \mathrm{mM} \mathrm{Cl})_{\text {in }}\right] \cdot C$, Current-voltage plots (as in $B$ ), but with symmetrical anionic solutions [ $(100 \mathrm{~mm} \mathrm{SCN}+10 \mathrm{~mm}$ $\mathrm{Cl})_{\text {out }}$ and $(100 \mathrm{~mm} \mathrm{SCN}+10 \mathrm{~mm} \mathrm{Cl})_{\text {in }}$ ]. Current amplitude has been normalized to D-aspartate-dependent currents measured at $-100 \mathrm{mV}$. D, Correlation of the current induced by $10 \mathrm{~mm}$ D-aspartate and the current blocked by $10 \mathrm{mM}$ DHK at $-80 \mathrm{mV}$. Squares represent data obtained in asymmetrical anionic solutions (as in B) and circles represent data obtained in symmetrical anion solutions (as in $C$ ). The slope of this line is 0.17 . flux of chloride, which is not stoichiometrically coupled to flux of glutamate (Wadiche et al., 1995b; Billups et al., 1996), and the fluxes of sodium, potassium, and protons, which are tightly coupled to glutamate flux (Kanner and Sharon, 1978; Stallcup et al., 1979; Erecinska et al., 1983; Nelson et al., 1983; Zerangue and Kavanaugh, 1996a). The glutamate transporter-associated flux of anions occurs through a pathway that is gated and selective, hallmarks of ion channel permeation. The relative permeabilities of different anions exhibited a remarkably wide range but fit well with Eisenman's first anion selectivity sequence (Eisenman, 1965) (Table 1). The channel pore diameter was at least $5 \AA$. No evidence was found for multiple occupancy or interaction between anions in the pore; the anion concentration dependence of the channel conductance and lack of anomalous mole fraction behavior are consistent with the permeating anion binding to a single site (Fig. 2). In addition, the sequence of permeabilities measured by reversal potentials was the same as the sequence of relative conductances. The conductance in the absence of glutamate (Fig. 7) demonstrates that channel gating and ion selectivity do not require the amino acid substrate (Bergles and Jahr, 1997).

A critical property distinguishing flux of glutamate and chloride was temperature dependence (Fig. $2 A, B$ ). In general, flux through a channel is relatively insensitive to temperature, with $Q_{10}$ values typically $<1.5$, because of the low-energy barriers associated with ionic diffusion (Hodgkin et al., 1952; Miller, 1987; Hille, 1992). The $Q_{10}$ value for the chloride current $(\sim 1)$ is consistent with such a mechanism, whereas the $Q_{10}$ for the coupled uptake current $(\sim 3)$ is consistent instead with energy requirements for large conformational transitions that occur during each transport cycle (Grunewald and Kanner, 1995).

Application of D-aspartate or L-glutamate to the intracellular surface of patches containing transporters show that the anion

$(+120 \mathrm{mV}$ to $-160 \mathrm{mV}) . B$, Correlation of transporter density with the D-aspartate-elicited anion conductance per unit area $\left(0 \mathrm{mV} ; \square, \mathrm{SCN}^{-} ; \bigcirc, \mathrm{Cl}^{-}\right)$. The number of transporters was calculated by dividing the charge blocked because of a saturating concentration of DHK by the product of the Boltzmann function's effective valance and the elementary charge $\left(n=Q_{\text {total }} / e_{0} z \delta=1.6 \times 10^{-19} * 0.34\right)$. The anion conductance in chloride $(0 \mathrm{mV})$ was calculated by first subtracting the D-aspartate-coupled transport current from the D-aspartate dependent total current (as in Fig. 1). The D-aspartate-dependent $\mathrm{Cl}^{-}$ and $\mathrm{SCN}^{-}$chord conductance per unit area at $0 \mathrm{mV}\left(\bigcirc, E_{\mathrm{rev}}=-22.3 \mathrm{mV} ; \square, E_{\mathrm{rev}}=-79.9 \mathrm{mV}\right.$, respectively) was then plotted as a function of transporter density. Linear regression of these data yielded a slope of $1.37 \times 10^{-17} \mathrm{~S} /$ transporter and $2.65 \times 10^{-16} \mathrm{~S}_{\text {transporter for } \mathrm{Cl}^{-} \text {and } \mathrm{SCN}}^{-}$, respectively. The average membrane area of oocytes was $2.85 \times 10^{7} \pm 0.14 \times 10^{7} \mu \mathrm{m}^{2}$ (Wadiche et al., 1995a). $C$, Voltage dependence of the unitary current - open probability product $\left(i * P_{\mathrm{o}}\right)$. D-Aspartate-dependent currents from outside-out EAAT1 patches were recorded with symmetrical anions $\left[(100 \mathrm{~mm} \mathrm{NaSCN}+10 \mathrm{NaCl})_{\text {out }} /(100 \mathrm{~mm} \mathrm{KSCN}+10 \mathrm{~mm} \mathrm{KCl})_{\text {in }}\right]$. The macroscopic current induced by aspartate $\left(N P_{\mathrm{o}} i\right)$ was divided by the number of transporters in each patch based on a chord conductance $(+80 \mathrm{mV})$ of $1.69 \times 10^{-16} \mathrm{~S} /$ transporter (see Materials and Methods). The mean number of transporters in these patches was $5.65 \pm 0.37 \times 10^{5}$ transporters $(n=7) . D$, Nonstationary noise analysis of EAAT1 currents. Representative current trace (top) and variance (bottom) resulting from 500 consecutive $625 \mathrm{msec}$ applications of $10 \mathrm{~mm}$ D-aspartate to an EAAT1-expressing outside-out patch $(0 \mathrm{mV})$. Middle traces represent an enlarged $200 \mathrm{msec}$ sub-record before, during, and after agonist application. Recording solutions are the same as in Figure 4. $E$, Mean current and variance plot during current deactivation (same patch as in $C$ ). Data were binned into 1000 points for clarity. The line drawn corresponds to the best fit to the equation: $\sigma^{2}=I i-I^{2} / N+C$ where $N=473962$ and $i=1.45 \mathrm{fA}$ and $C=0.054 \mathrm{pA}^{2}$. The number of transporters $(N)$ was determined as in $B$ given $2.65 \times 10^{-16} \mathrm{~S} /$ transporters at $0 \mathrm{mV}$. $F$, Difference of the average spectra in the presence and absence of $10 \mathrm{~mm}$ D-aspartate. Five hundred sweeps $(600 \mathrm{msec}$ each) were acquired at $10 \mathrm{kHz}$ and filtered at $5 \mathrm{kHz}$. Same patch as in $D$. 


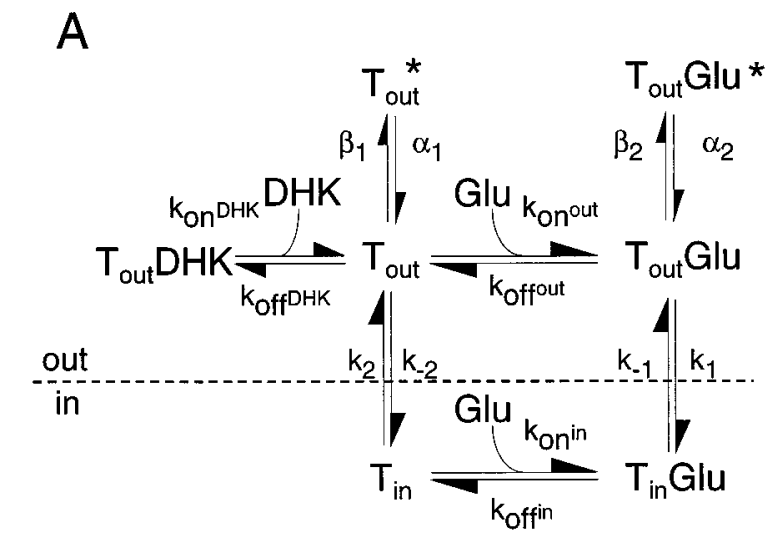

B
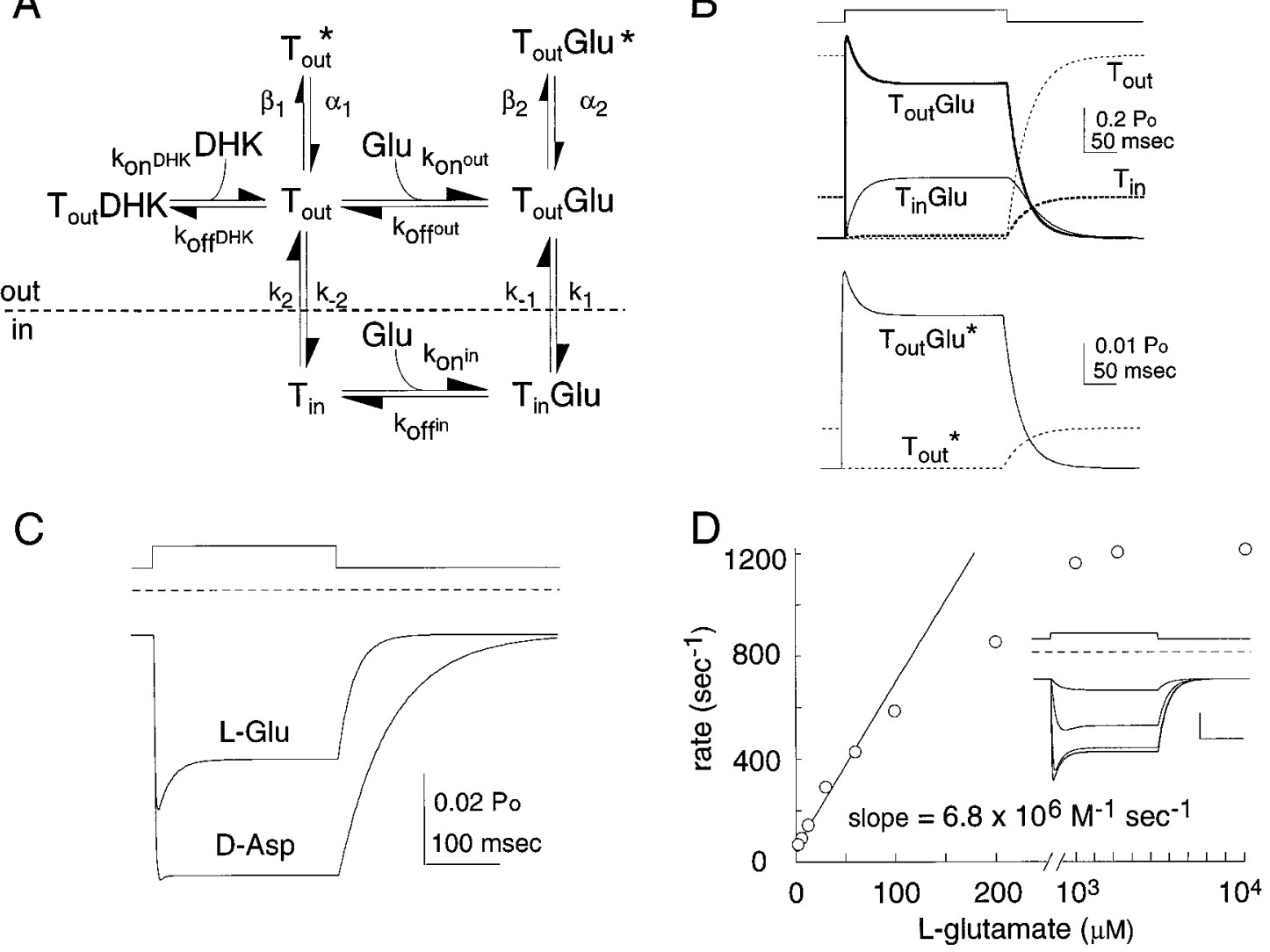

Figure 8. Computer simulation. A, Kinetic model of L-glutamate and D-aspartate transport and anion conductance. Model parameters were obtained by least squares fitting of data and fit an average pulse of L-glutamate of D-aspartate. The microscopic rates were as follows: $k_{\text {on out }}=6.8 \times 10^{6} \mathrm{M}^{-1} \mathrm{sec}^{-1}$, $k_{\text {off }}^{\text {out }}=30.6 \mathrm{sec}^{-1} ; k_{1}=16.0 \mathrm{sec}^{-1} ; k_{-1}=2.9 \mathrm{sec}^{-1} ; k_{\text {on }}$ in $=6.8 \times 10^{6} \mathrm{M}^{-1} \mathrm{sec}^{-1} ; k_{\text {off }}^{\text {in }}=37.2 \mathrm{sec}^{-1} ; k_{2}=885 \mathrm{sec}^{-1} ; k_{-2}=200 \mathrm{sec}^{-1} ; \alpha_{1}=8094 \mathrm{sec}^{-1}$; $\beta_{1}=100 \mathrm{sec}^{-1} ; \alpha_{2}=1260 \mathrm{sec}^{-1} ; \beta_{2}=70 \mathrm{sec}^{-1}$. D-Aspartate data were fit with identical rates for agonist independent states and $k_{\text {off }}$ out $=7.6$ sec ${ }^{-1}$; $k_{1}=7.3 \mathrm{sec}^{-1} ; k_{-1}=1.0 \mathrm{sec}^{-1} ; k_{\text {off }}^{\text {in }}=165 \mathrm{sec}^{-1} ; \alpha_{2}=978 \mathrm{sec}^{-1}$, and $\beta_{2}=70 \mathrm{sec}^{-1}$. DHK binding was assigned as $6.8 \times 10^{6} \mathrm{M}^{-1} \mathrm{sec}^{-1}$, whereas DHK unbinding $\left(k d h k_{\text {out }}\right)=97 \mathrm{sec}^{-1} . B$. Probability of occupancy for each state in the kinetic scheme shown in $A$ during a 250 msec pulse of $10 \mathrm{~mm}$ L-glutamate. The top traces show the nonconducting states: the unliganded states are represented by dashed lines $\left(T_{\text {out }}\right.$ and $T_{\text {in }} ;$ bold $)$, whereas the liganded states are represented by a solid line $\left(T_{o u t}\right.$ Glu; bold and $\left.T_{i n} G l u\right)$. The bottom traces show the occupancy of the anion conducting states. Note the different scale bars. $C$, Simulation of a $250 \mathrm{msec}$ pulse of $10 \mathrm{~mm}$ L-glutamate or D-aspartate $(A)$. The channel's steady-state open probability was determined from nonstationary noise analysis (Fig. 4) and the DHK-blocked currents (Fig. 6). The fraction of transporters in either conducting state $T G l u_{\text {open }}$ or $T_{\text {open }}$ are plotted as a function of time. $D$, Concentration dependence of the time constant for activation of L-glutamate currents for the kinetic scheme shown in $A$. The time constants for the activation and deactivation were calculated by fitting the current records to a single exponential. The limiting slope for the activation rate equals $6.8 \times 10^{6} \mathrm{M}^{-1} \mathrm{sec}^{-1}$. Inset, L-Glutamate concentration dependence of the open probability $(1 \mu \mathrm{M}, 10$ $\mu \mathrm{M}, 100 \mu \mathrm{M}$, and $1 \mathrm{mM})$. The model's apparent affinity at steady state is $7 \mu \mathrm{M}$.

Table 2. Kinetic parameters

\begin{tabular}{llllc} 
& L-Glutamate & L-Glutamate model & D-Aspartate & D-Aspartate model \\
\hline$\tau$ activation (msec) & $0.96 \pm 0.1(19)$ & 0.83 & $2.66 \pm 0.2(19)$ & 1.5 \\
$\tau$ deactivation (msec) & $22.8 \pm 3.9(9)$ & 22.5 & $75.1 \pm 10.5(9)$ & 72.4 \\
$\tau$ inactivation (msec) & $14.1 \pm 2.4(18)$ & 18.3 & $85.4 \pm 15.7(11)$ & 94.7 \\
Peak/steady-state ratio & $1.56 \pm 0.1(11)$ & 1.5 & $1.05 \pm 0.02(17)$ & 1.05
\end{tabular}

Kinetic parameters were determined at $-80 \mathrm{mV}$ with a $10 \mathrm{~mm}$ application of L-glutamate or D-aspartate.

current can be activated by reverse transport [also see Billups et al. (1996); Kavanaugh et al. (1997)]. The apparent affinity of EAAT1 for D-aspartate on the internal side of the membrane was $\sim 10$-fold lower than at the external binding site with the same ionic conditions. Activation of the anion current by intracellular substrate was dependent on the trans cations present (Fig. 3C). Reverse transport currents were seen when $\mathrm{K}^{+}$but not choline was present as the external cation. A small but significant current was also observed when $\mathrm{K}^{+}$was substituted by $\mathrm{Na}^{+}$.

\section{Predicted unitary properties of the anion channel}

Evidence that glutamate transporter substrates induce channellike current fluctuations (Tachibana and Kaneko, 1988; Picaud et al., 1995b; Larsson et al., 1996) suggests that the $\mathrm{Cl}^{-}$conductance is stochastically gated. Unitary events and current noise have also 
been associated with monoamine transporters (Cammack and Schwartz, 1996; Galli et al., 1996; Lin et al., 1996). No glutamatedependent unitary events were directly resolved in membrane patches containing EAAT1 transporters. Noise analysis of glutamate transporter currents in photoreceptors indicates that glutamate activates a channel with a unitary conductance of $0.5-0.7 \mathrm{pS}$ (Tachibana and Kaneko, 1988; Picaud et al., 1995b; Larsson et al., 1996). However, glutamate induced much less current noise in EAAT1 patches. Stationary and nonstationary analysis were consistent with a chloride channel conductance approximately three orders of magnitude smaller than predicted in photoreceptors. The reason for this difference is unclear, but it may be attributable to differences between EAAT1 and the excitatory amino acid transporter subtypes found in photoreceptors. Although all cloned glutamate transporters examined to date mediate $\mathrm{Cl}^{-}$ flux, its magnitude relative to glutamate flux varies (Wadiche et al., 1995b; Eliasof et al., 1998). In oocytes expressing EAAT5, a transporter that appears to be abundantly expressed in retinal photoreceptor terminals, glutamate activates currents carried predominantly by chloride (Arriza et al., 1997; Eliasof et al., 1998). The unitary properties of the cloned EAAT5 transporter expressed in oocytes have not yet been examined, but its conductance may be much larger than that of EAAT1. It is also possible that the open time of the EAAT1 channel is much briefer, resulting in an underestimate of the conductance caused by bandwidth limitation.

\section{Transporter and channel kinetics}

When outside-out patches of excised membranes were exposed to rapid pulses of glutamate, anion currents activated rapidly and partially inactivated during the glutamate pulse (Fig. 4) [also see Otis et al. (1997); Bergles et al. (1997); Otis and Jahr (1998)]. In the context of a cyclic transport scheme such as the Na-K pump, transient currents induced by concentration jumps are presumed to reflect early charge translocating steps in the cycle (Borlinghaus et al., 1987). The EAAT1 current observed after a glutamate pulse indicates that channel activation occurs soon after a rapid glutamate binding step. The cyclic kinetic model predicts a nearly synchronous channel opening followed by relaxation (or desynchronization) to a steady-state distribution of open and closed states. The rate constants in the transport cycle, together with the rates leading into and out of the open channel states, determine the kinetics of the current after a concentration jump. There was a twofold difference in turnover rates between L-glutamate and D-aspartate, and striking differences in macroscopic anion current kinetics were observed. Because L-glutamate and D-aspartate are transported at different rates, it may be inferred that the ratelimiting step in transport is an amino acid-bound state transition. We tentatively assign this step to a gating event involved in amino acid translocation across the membrane. The simulation of a cyclical transport scheme with branching open channel states demonstrates how the difference in transport rates can account for differences in anion current activation and deactivation as well as differences in peak/steady-state anion current ratios (Fig. 8). Furthermore, the model predicts that at very low concentrations of amino acid, the activation rate of the anion current reflects the binding rate of the amino acid to the transporter (Figs. 5B, 8D). At synaptic time scales (Clements et al., 1992), transporter density and glutamate binding rates will be critical determinants of the transporters' roles in buffering synaptically released glutamate (Diamond and Jahr, 1997). The experimentally measured limiting slope of the anion current activation rate by low concen- trations of glutamate was $6.8 \times 10^{6} \mathrm{M}^{-1} \mathrm{sec}^{-1}$. This rate is similar to the estimated rate of glutamate binding to AMPA receptors (Jonas et al., 1993). The predicted glutamate unbinding rate at $25^{\circ} \mathrm{C}$ leads to the somewhat paradoxical result that after binding to the transporter, a molecule of glutamate has a significantly higher probability of unbinding than of being transported $\left(P_{\text {un }}\right.$ bind $\left./ P_{\text {transport }}>30.6 \mathrm{sec}^{-1} / 16 \mathrm{sec}^{-1}\right)$ (Fig. 8 , legend). This suggests that a molecule of glutamate may bind to and unbind from multiple transporters, and perhaps receptors, before being removed from the extracellular space. In some conditions, synaptically released glutamate can diffuse away from the cleft and activate presynaptic receptors (Scanziani et al., 1997). Furthermore, temperature effects on transport appear to influence the extent to which glutamate can diffuse to neighboring synapses (Asztely et al., 1997). If a significant fraction of released glutamate is bound by transporters near the synaptic cleft (Otis et al., 1997), an increase in temperature may reduce the escape of glutamate primarily by decreasing the relative probability of unbinding before transport.

In summary, transporter currents recorded in patches are consistent with the occurrence of rapid state transitions, including glutamate binding and channel opening, within a relatively slow overall transport cycle. Further work to precisely correlate open channel states to states in the transport cycle will provide a powerful technique for monitoring transporter function with high time resolution.

\section{REFERENCES}

Anderson CR, Stevens CF (1973) Voltage clamp analysis of acetylcholine produced end-plate current fluctuations at frog neuromuscular junction. J Physiol (Lond) 235:655-691.

Arriza JL, Kavanaugh MP, Fairman WA, Wu YN, Murdoch GH, North RA, Amara SG (1993) Cloning and expression of a human neutral amino acid transporter with structural similarity to the glutamate transporter gene family. J Biol Chem 268:15329-15332.

Arriza JL, Eliasof S, Kavanaugh MP, Amara SG (1997) Excitatory amino acid transporter 5, a retinal glutamate transporter coupled to a chloride conductance. Proc Natl Acad Sci USA 94:4155-4160.

Asztely F, Erdemli G, Kullmann DM (1997) Extrasynaptic glutamate spillover in the hippocampus: dependence on temperature and the role of active glutamate uptake. Neuron 18:281-293.

Barbour B, Brew H, Attwell D (1988) Electrogenic glutamate uptake in glial cells is activated by intracellular potassium. Nature 335:433-435.

Bergles DE, Jahr CE (1997) Synaptic activation of glutamate transporters in hippocampal astrocytes. Neuron 19:1297-1308.

Bergles DE, Dzubay JA, Jahr CE (1997) Glutamate transporter currents in bergmann glial cells follow the time course of extrasynaptic glutamate. Proc Natl Acad Sci USA 94:14821-14825.

Billups B, Rossi D, Attwell D (1996) Anion conductance behavior of the glutamate uptake carrier in salamander retinal glial cells. J Neurosci 16:6722-6731.

Borlinghaus R, Apell HJ, Läuger P (1987) Fast charge translocations associated with partial reactions of the Na,K-pump. I. Current and voltage transients after photochemical release of ATP. J Membr Biol 97:161-178.

Cammack JN, Schwartz EA (1996) Channel behavior in a $\gamma$-aminobutyrate transporter. Proc Natl Acad Sci USA 93:723-727.

Clements JD, Lester RA, Tong G, Jahr CE, Westbrook GL (1992) The time course of glutamate in the synaptic cleft. Science 258:1498-1501.

Diamond JS, Jahr CE (1997) Transporters buffer synaptically released glutamate on a submillisecond time scale. J Neurosci 17:4672-4687.

Eisenman G (1965) Some elementary factors involved in specific ion permeation. In: International Congress of Physical Science, pp 489506. Tokyo.

Eliasof S, Jahr CE (1996) Retinal glial cell glutamate transporter is coupled to an anionic conductance. Proc Natl Acad Sci USA 93:4153-4158.

Eliasof S, Arriza JL, Leighton BH, Kavanaugh MP, Amara SG (1998) 
Excitatory amino acid transporters of the salamander retina: identification, localization, and function. J Neurosci 18:698-712.

Erecinska M, Wantorsky D, Wilson DF (1983) Aspartate transport in synaptosomes from rat brain. J Biol Chem 258:9069-9077.

Fairman WA, Vandenberg RJ, Arriza JL, Kavanaugh MP, Amara SG (1995) An excitatory amino-acid transporter with properties of a ligand-gated chloride channel. Nature 375:599-603.

Galli A, Blakely RD, DeFelice LJ (1996) Norepinephrine transporters have channel modes of conduction. Proc Natl Acad Sci USA 93:8671-8676.

Grant GB, Dowling JE (1995) A glutamate-activated chloride current in cone-driven ON bipolar cells of the white perch retina. J Neurosci 15:3852-3862.

Grunewald M, Kanner B (1995) Conformational changes monitored on the glutamate transporter GLT-1 indicate the existence of two neurotransmitter-bound states. J Biol Chem 270:17017-17024.

Halm DR, Frizzell RA (1992) Anion permeation in an apical membrane chloride channel of a secretory epithelial cell. J Gen Physiol 99:339-366.

Hille B (1992) Ionic channels of excitable membranes, Ed 2. Sunderland, MA: Sinauer.

Hodgkin AL, Huxley AF, Katz B (1952) Measurement of currentvoltage relations in the membrane of the giant axon of Loligo. J Physiol (Lond) 116:424-448.

Jonas P, Major G, Sakmann B (1993) Quantal components of unitary EPSCs at the mossy fibre synapse on CA3 pyramidal cells of rat hippocampus. J Physiol (Lond) 472:615-663.

Kanner BI, Sharon I (1978) Active transport of L-glutamate by membrane vesicles isolated from rat brain. Biochemistry 17:3949-3953.

Kavanaugh MP (1993) Voltage dependence of facilitated arginine flux mediated by the system $y+$ basic amino acid transporter. Biochemistry 32:5781-5785.

Kavanaugh MP, Bendahan A, Zerangue N, Zhang Y, Kanner BI (1997) Mutation of an amino acid residue influencing potassium coupling in the glutamate transporter GLT-1 induces obligate exchange. J Biol Chem 272:1703-1708.

Klamo EM, Drew ME, Landfear SM, Kavanaugh MP (1996) Kinetics and stoichiometry of a proton/myo-inositol cotransporter. J Biol Chem 271:14937-14943.

Larsson HP, Picaud SA, Werblin FS, Lecar H (1996) Noise analysis of the glutamate-activated current in photoreceptors. Biophys $\mathrm{J}$ 70:733-742.

Läuger P (1991) Electrogenic ion pumps. Sunderland, MA: Sinauer.

Lehre KP, Levy LM, Ottersen OP, Storm-Mathisen J, Danbolt NC (1995) Differential expression of two glial glutamate transporters in the rat brain: quantitative and immunocytochemical observations. J Neurosci 15:1835-1853.

Lin F, Lester HA, Mager S (1996) Single channel currents produced by the serotonin transporter and analysis of a mutation affecting ion permeation. Biophys J 71:3126-3135.

Maconochie DJ, Knight DE (1989) A method for making solution changes in the sub-millisecond range at the tip of a patch pipette. Pflügers Arch 414:589-596.

Mager S, Naeve J, Quick M, Labarca C, Davidson N, Lester HA (1993)
Steady states, charge movements, and rates for a cloned GABA transporter expressed in Xenopus oocytes. Neuron 10:177-188.

Malandro MS, Kilberg MS (1996) Molecular biology of mammalian amino acid transporters. Annu Rev Biochem 65:305-336.

Miller C (1987) How ion channel proteins work. In: Neuromodulation (Kaczmarek LK, Levitan IB, eds), pp 39-61. New York: Oxford.

Nelson PJ, Dean GE, Aronson PS, Rudnick G (1983) Hydrogen ion cotransport by the renal brush border glutamate transporter. Biochemistry 22:5459-5463.

Otis TS, Jahr CE (1998) Anion currents and predicted glutamate flux through a neuronal glutamate transporter. J Neurosci, in press.

Otis TS, Kavanaugh MP, Jahr CE (1997) Postsynaptic glutamate transport at the climbing fiber-Purkinje cell synapse. Science 277:1515-1518.

Picaud SA, Larsson HP, Wellis DP, Lecar H, Werblin FS (1995a) Cone photoreceptors respond to their own glutamate release in the tiger salamander. Proc Natl Acad Sci USA 92:9417-9421.

Picaud SA, Larsson HP, Grant GB, Lecar H, Werblin FS (1995b) Glutamate-gated chloride channel with glutamate transporter-like properties in cone photoreceptors of the tiger salamander. J Neurophysiol 74:1760-1771.

Rothstein JD, Martin L, Levey AI, Dykes-Hoberg M, Jin L, Wu D, Nash N, Kuncl RW (1994) Localization of neuronal and glial glutamate transporters. Neuron 13:713-725.

Sarantis M, Everett K, Attwell D (1988) A presynaptic action of glutamate at the cone output synapse. Nature 332:451-453.

Scanziani M, Salin PA, Vogt KE, Malenka RC, Nicoll RA (1997) Usedependent increases in glutamate concentration activate presynaptic metabotropic glutamate receptors. Nature 385:630-634.

Sigworth FJ (1980) The variance of sodium current fluctuations at the node of ranvier. J Physiol (Lond) 307:97-129.

Stallcup WB, Bulloch K, Baetge EE (1979) Coupled transport of glutamate and sodium in a cerebellar nerve cell line. J Neurochem 32:57-65.

Szatkowski M, Barbour B, Attwell D (1990) Non-vesicular release of glutamate from glial cells by reversed electrogenic glutamate uptake. Nature 348:443-446.

Tachibana M, Kaneko A (1988) L-Glutamate-induced depolarization in solitary photoreceptors: a process that may contribute to the interaction between photoreceptors in situ. Proc Natl Acad Sci USA 85:5315-5319.

Wadiche JI, Arriza JL, Amara SG, Kavanaugh MP (1995a) Kinetics of a human glutamate transporter. Neuron 14:1019-1027.

Wadiche JI, Amara SG, Kavanaugh MP (1995b) Ion fluxes associated with excitatory amino acid transport. Neuron 15:721-728.

Yamada K, Watanabe M, Shibata T, Tanaka K, Wada K, Inoue Y (1996) EAAT4 is a post-synaptic glutamate transporter at Purkinje cell synapses. NeuroReport 7:2013-2017.

Zampighi GA, Kreman M, Boorer KJ, Loo DD, Bezanilla F, Chandy G, Hall JE, Wright EM (1995) A method for determining the unitary functional capacity of cloned channels and transporters expressed in Xenopus laevis oocytes. J Membr Biol 148:65-78.

Zerangue N, Kavanaugh MP (1996a) Flux coupling in a neuronal glutamate transporter. Nature 383:634-637.

Zerangue N, Kavanaugh MP (1996b) ASCT-1 is a neutral amino acid exchanger with chloride channel activity. J Biol Chem 271:2799127994. 